\title{
MODELAGEM DA LACTAÇÃO, PRODUÇÃO DE LEITE E COMPORTAMENTO DE AMAMENTAÇÃO EM GADO DE CORTE
}

\section{ANA CAROLINA ESPASANDIN MEDEROS}

Engenheira Agrônoma

Orientador: Prof. Dr. IRINEU UMBERTO PACKER

\begin{abstract}
Dissertação apresentada à Escola Superior de Agricultura "Luiz de Queiroz", Universidade de São Paulo, para obtenção do título de Mestre em Agronomia, Área de Concentração: Ciência Animal e Pastagens
\end{abstract}

PIRACICABA

Estado de São Paulo - Brasil

Julho, 2000 


\section{Dados Internacionais de Catalogação na Publicação (CIP) DIVISĀO DE BIBLIOTECA E DOCUMENTAÇĀO - Campus "Luiz de QueirOz" /USP}

\section{Espasandin Mederos, Ana Carolina}

Modelagem da lactação, produção de leite e comportamento de amamentação em gado de corte / Ana Carolina Espasandin Medeiros. -- Piracicaba, 2000.

$$
67 \mathrm{p} \text {. }
$$

Dissertação (mestrado) - Escola Superior de Agricultura Luiz de Queiroz, 2000. Bibliografia.

1. Aleitamento 2. Bovino de corte 3. Comportamento animal 4. Lactação animal 5. Leite 6. Sistema de produção I. Título

CDD 636.213 


\section{AGRADECIMENTOS}

Ao Professor Packer pela sua aceitação, orientação e gentileza que proporcoinou em todo momento.

A todo o pessoal da EMBRAPA pela sua gentileza e carinho e especialmente ao Dr. Maurício, Nacir, Adão, Cessão, Celso Tadeu e Vera, pela sua ajuda durante todo o trabalho realizado na EMBRAPA.

A Karina pela sua ajuda, companhia e amizade durante a fase de campo na EMBRAPA.

Aos meus amigos Maria Eugenia e Rodrigo, Juliana, Luisa e Luiz, e Leandro que acompanharam no pessoal e laboral durante todo o mestrado e que graças a eles foi possivel uma fácil adaptaçãol à vida no Brasil.

Ao Enrique pela sua amizade, ajuda e companhia.

A Vera, Cláudia e Ike e D. Maria pela sua ajuda, solidariedade e amizade.

Ao Cláudio pela sua grande ajuda no processamento e análise do trabalho.

A Celine (pós graduação-ESALQ) quem desde o primeiro momento sempre ajudou e orientou em todo o relativo aos processos, relatórios e documentos dos extrangeiros e do convênio PEC/PG.

Aos professores Sila C. da Silva, Valdomiro Miyada, Jose E. Possebon Cyrino, Dante P. Lanna e Jose Fernando Menten pela sua gentileza e colaboração desde o começo do mestrado.

A todo o pessoal da ESALQ pela gentileza com que sempre me receberam.

A minha família pelo seu constante amor, apoio e compreensão.

Ao Convênio PEC/PG, e a ESALQ pela oportunidade oferecida para realização do Mestrado nesta Instituição.

A Universidad de la República Oriental del Uruguay por permitir a realização do Mestrado no Brasil. 


\section{SUMÁRIO}

Página

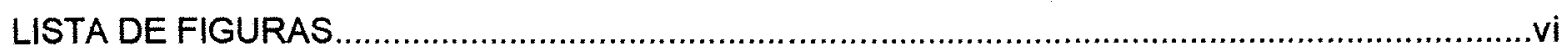

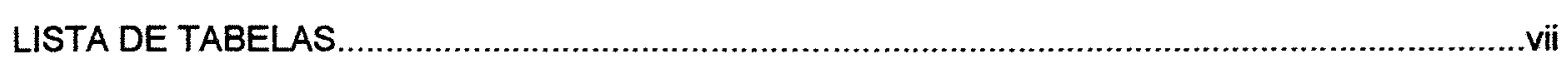

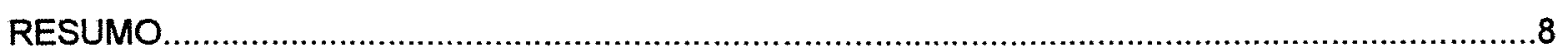

SUMMARY

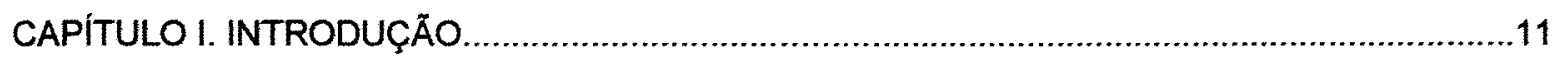

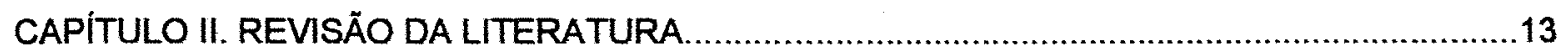

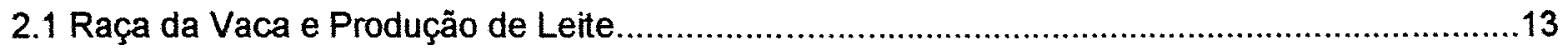

2.2 Alimentação e Produção de Leite .....................................................................................14

2.3 Produção de Leite e crescimento do bezerro....................................................................15

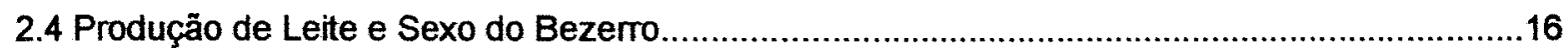

2.5 Comportamento de Amamentação.................................................................................18

2.6 Técnicas para Estimação da Produção de Leite..................................................................19

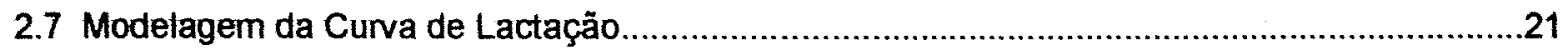

CAPÍTULO III. Produção e leite e comportamento de amamentação em cinco

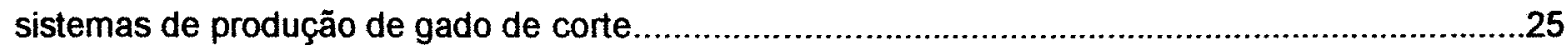

Resumo

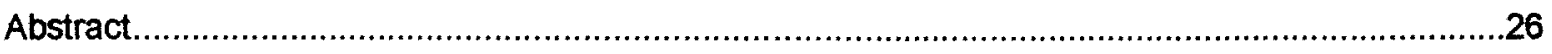

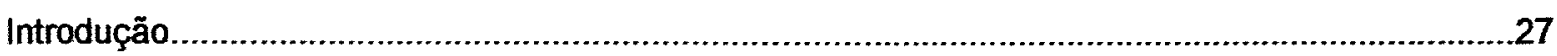

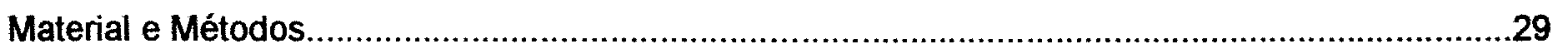

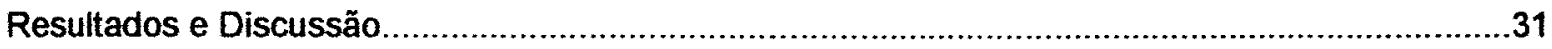

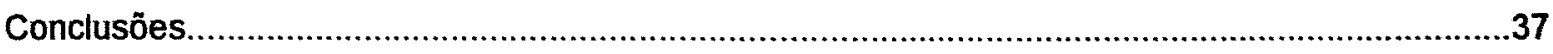

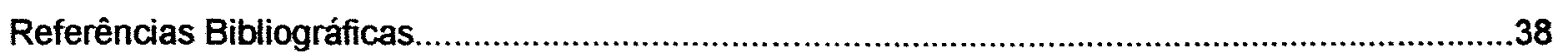

CAPITULO IV. Estimativas de parâmetros genéticos da produção de leite em gado de corte

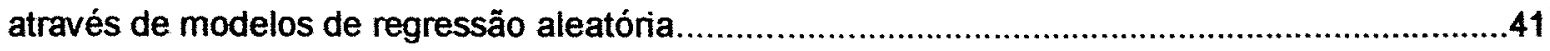

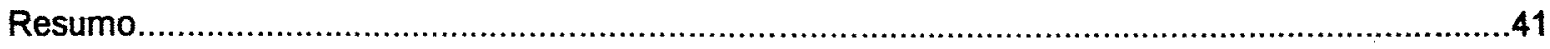

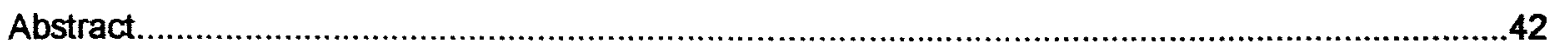

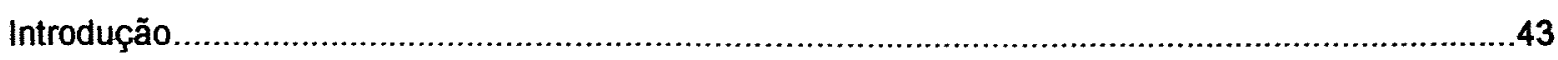

Material e Métodos

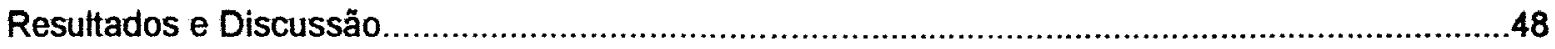




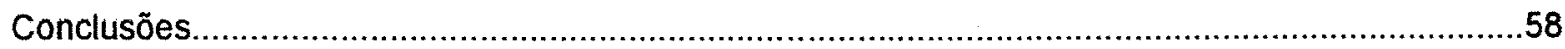

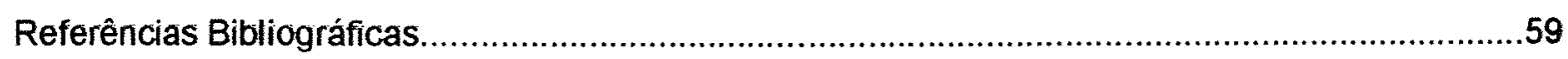

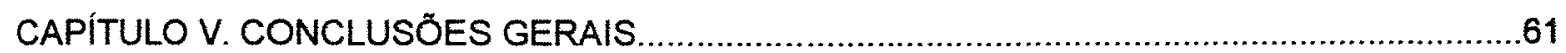

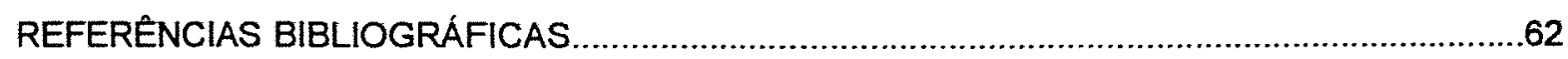




\section{LISTA DE FIGURAS}

Página

\section{CAPITULO III}

Figura 1. Produção de leite de leite durante a lactação em cinco sistemas de produção. .31

Figura 2. Tempo diário de amamentação aos 60,120 e 180 dias após o parto. 34

\section{CAPITULO IV}

Figura 1. Médias e desvios padrão dos valores genéticos estimados para a produção de leite em cada controle individual de produção. .52

Figura 2. Estimativas da herdabilidade da produção de leite para cada dia de controle individual de produção. .53

Figura 3. (Co)variâncias genético aditivas para a produção de leite nos controles individuais de produção.. .54

Figura 4. (Co)variâncias de ambiente permanente para a produção de leite nos controles individuais de produção. .54

Figura 5. (Co)variâncias fenotípicas para a produção de leite nos controles individuais de produção. .55

Figura 6. Correlações genéticas entre os controles individuais de produção leiteira. .56

Figura 7. Correlações de ambiente permanente entre os controles individuais de produção leiteira. .56

Figura 8. Correlações fenotípicas entre os controles individuais de produção leiteira. 57 


\section{LISTA DE TABELAS}

Página

\section{CAPITULO III}

Tabela 1. Produção de leite nos cinco sistemas de produção em três momentos da lactação.

Tabela 2. Tempo de duração de cada mamada (minutos) para cinco sistemas de produção .33

Tabela 3. Tempo diário de amamentação nos sistemas de produção avaliados. .33

Tabela 4. Ganhos diários pré desmama e pesos à desmama de bezerros puros e cruzados durante a fase pré desmama. .35

\section{CAPITULO IV}

Tabela 1. Número de controles individuais de produção de leite por classe definida.

Tabela 2. Estimativas de covariâncias genéticas para os coeficientes de regressão aleatória, e variâncias de ambiente permanente para produção de leite

Tabela 3. Estimativa dos coeficientes de regressão aleatória para os efeitos genético aditivos para produção de leite $(\mathrm{kg})$ em 10 animais.

Tabela 4. Estimativa dos coeficientes de regressão aleatória para os efeitos de ambiente permanente sobre a produção de leite $(\mathrm{kg})$ de 10 animais. 


\title{
MODELAGEM DA LACTAÇÃO, PRODUÇÃO DE LEITE E COMPORTAMENTO DE AMAMENTAÇÃO EM GADO DE CORTE
}

\author{
Autor: Ana Carolina Espasandin \\ Orientador: Irineu Umberto Packer
}

\section{RESUMO}

Foram estudadas a produção de leite de vacas Nelore e o comportamento de amamentação de bezerros em diferentes sistemas de produção (SIST): NR-Nelore Referência (manejo tradicional); NI-Nelore Intensivo; e três cruzamentos CN-Canchim $\times$ Nelore, AN-Angus $\times$ Nelore e SN-Simental $x$ Nelore, em regime intensivo. Em três momento da lactação $(60,120$ e 180 dias após o parto) nos bezerros foram medidas a freqüência e duração das mamadas, e ganho diário de peso $(\mathrm{Kg} / \mathrm{dia})$. A produção de leite apresentou efeito significativo do momento da lactação e da interação sistema de produção por momento da lactação. A produção de leite não teve relação direta com o comportamento de amamentação nem o ganho de peso dos bezerros dos diferentes sistemas de produção. Condições deficientes de alimentação não resultaram em menores produções de leite de vacas Nelore, mas sim em acentuadas perdas de peso durante a estação de monta no sistema NR. O tempo diánio de amamentação apresentou quedas significativas no sistema extensivo durante a lactação, enquanto que os sistemas intensivos não mudam ou aumentam os minutos de amamentação por dia. Para as condiçōes nas quais o experimento foi desenvolvido, os bezerros cruzados apresentaram os melhores desempenhos durante a fase pré desmama, em comparação com os sistemas puros.Foram estimados parâmetros genéticos para a produção de leite de vacas de corte através da análise de controles individuais de produção (CIP) usando modelos de regressão aleatória. As análises da produção de leite foram realizadas ajustando polinômio de Legendre $\left(2^{\circ} \mathrm{grau}\right)$. Foram considerados como efeitos fixos: grupo contemporâneo (ano-mês do CIP), grupo genético da vaca e do bezerro, e as covariáveis peso vivo das vacas e bezerros e como aleatórios o efeito genético aditivo de animal, e o ambiente permanente e temporário. Foram estimadas as herdabilidades e correlações genéticas, ambientais e fenotípicas da produção de leite para cada dia de controle individual de produção. As estimativas foram obtidas por máxima verossimilhança restrita usando o programa DXMRR. As herdabilidades para os diferentes controles leiteiros apresentaram valores levemente superiores no início e claramente maiores no final da lactação. A magnitude das estimativas de herdabilidade neste trabalho $(0,23-0,41)$ encontra-se dentro do observado nos trabalhos publicados para gado de leite. As variâncias genéticas aditivas foram inferiores no começo e aumentaram no final da lactação. Conforme 
esperado e em concordância com os trabalhos revisados as correlações genéticas apresentam valores altos e positivos entre controles sucessivos $(0,98-1,0)$, diminuindo até valores negativos quando os intervalos entre controles superaram os 200 dias. 


\title{
MODELAGEM DA LACTAÇÃO, PRODUÇÃO DE LEITE E COMPORTAMENTO DE AMAMENTAÇÃO EM GADO DE CORTE
}

\author{
Autor: Ana Carolina Espasandin \\ Orientador: Irineu Umberto Packer
}

\section{SUMMARY}

Milk yield and suckling behaviour in calves and cows Nellore of different production systems: NRNellore Reference, NI- Intensive Nellore; and three crossbreeding systems CN-Canchim-Nellore, AN-Angus-Nellore and SN-Simmental-Nellore in intensive management, was studied. Measurements for calves were bouts and lenght of suckles, and daily gain ( $\mathrm{Kg} /$ day) in a three moments of lactation (60,120 and 180 days after calving). Moment of lactation and production system by lactation moment interaction was a significant effect in milk yield. Milk yield did not show any relationship with suckling behaviour or daily gain in calves. Extensive grazing conditions did not cause lesser levels in milk yield of Nellore cows althoughthey determined significant weight losses $(80 \mathrm{Kg})$ during the breeding season in the NR system. Daily lenght of suckling during lactation phase decreased in the NR system ( 20 vs. 9 minutes/day), and sustained or increased in intensive systems. Crossed calves showed higher daily gain and weaning weight than pure bred. Genetic parameters for milk yield of beef cows were estimated by test days analysis with random regression models. The analysis for milk production were made using order two Legendre's polynomial. Contemporary group (year-month of test day) and genetic group of cow and calf were considered as fixed effects; live weight of cows and calves were analyzed as covariates, and additive genetic effect of animals and permanent and temporaryenvironmental effects were considered as random effects. Hentability and genetic, phenotipic and emvironmental correlations of milk yield with each test day were estimated. Estimates were obtained by maximum restricted likelihood using DxMRR program (Meyer, 1998). Heritabilities for milk yield in test day showed slightly higer values at the beginning and significantly higher values at the end of the lactation period. Estimatives of heritability found in this study $(0,23-0,41)$ are similar to those reported in publications for dairy cattle. Additive genetic variances were lower at the beginning and higher at the end of the lactation period. As expected and in agreement with previous literature, genetic correlation showed high and positive values between subsequents tst days $(0,98-1,0)$, decresing till negative values when intervals between test days were higher than 200 days. 


\section{CAPITULO I INTRODUÇÃO}

Os sistemas de criação extensivos em regime de pasto sujeitam aos animais a escassez periódica de forragem, comprometendo seu desenvolvimento e eficiência reprodutiva. Além disso, o baixo potencial genético dos rebanhos, ou a não adequação dos mesmos ao ambiente de manejo, constituem os principais entraves do setor produtivo (Lanna, 1997).

A viabilização de sistemas intensivos de produção de carne bovina depende da utilização de animais de grupos genéticos capazes de responder satisfatoriamente aos investimentos feitos no setor. Os cruzamentos entre raças tem muito a contribuir para aumentar a produção e produtividade da pecuária bovina de corte nacional, pois permite a combinação de características de diferentes raças e a obtenção do vigor híbrido e complementariedade naquelas características que o expressam (Fries, 1997).

Muito pouco se sabe sobre a eficiência produtiva de cada sistema de cruzamento. Os sistemas de cruzamentos resultam em diferentes graus de heterose, possuem vantagens e desvantagens e a sua avaliação deve prever a continuidade dos mesmos. Torna-se necessário determinar mediante pesquisa, aqueles cruzamentos que apresentam maior vigor hibrido e que combinem características econômicas desejáveis, para os diferentes tipos de manejo e regiões do pais (Alencar et al., 1995; Trematore et al., 1996).

A vaca é a estrutura primária na industria de carne. Ela pode ser caracterizada pelo seu tamanho, requerimentos de energia, performance reprodutiva, produção e composição do leite (Fiss and Wilton, 1992).

A produção de leite das vacas é característica importante na pecuária de corte, uma vez que grande parte dos nutrientes ingeridos pelos bezerros nos primeiros meses de vida é proveniente do leite matemo. Desse modo, as produções de leite das vacas influenciam o deservolvimento dos bezerros (Cruz et al., 1997). 
A eficiência de produção no sistema vaca-bezerro pode ser definida em termos do sucesso da conversão da energia alimentar em peso de bezerros à desmama. A variação em eficiência biológica existe entre raças e cruzamentos de raças. Diferenças em potencial genético para produção tem sido sugeridas como afetando a eficiência global de produção (Jenquins e Ferrel, 1992).

Alguns trabalhos tem demonstrado que entre vacas do mesmo potencial genético para peso maduro, aquelas com maiores potenciais de produção de leite apresentam as menores eficiências de produção. Montaño Bermúdez e Nielsen (1990) observaram uma relação negativa entre produção de leite potencial, taxa de prenhez e porcentagem de saídas de bezerros.

Vacas com altas produções de leite apresentam maiores requerimentos de energia metabolizável quando comparadas com as menos produtoras. Se as fontes de alimentação são limitadas, as reservas corporais podem ser utilizadas para cobrir requerimentos nutricionais (Jenkins e Ferrel, 1992).

A performance das raças cruzadas e as mudanças resultantes do incremento do peso das vacas e da produção de leite são variáveis essenciais na determinação dos sistemas de cruzamentos que maximizam os lucros na produção de carne (Mc Morris e Wilton, 1986).

Devido a que o peso à desmama é influenciado pela produção de leite da sua mãe, a escolha de um genótipo de vacas apropriado beneficia a produção do sistema vaca-bezerro (Miller et al, 1999).

Muitos trabalhos tem sido publicados em relação as metodologias utilizadas para estudar as curvas de lactação em gado de corte e leite (Jamrozik et al., 1997; Faro et al., 2000).

A maioria dos trabalhos concluem que o uso de modelos de regressão aleatória para avaliar os controles leiteiros consiste em uma técnica muito apropriada para análise de estes dados em particular (Jamrozik et al., 1997; Meyer, 2000).

Em função dos antecedentes, o trabaho centraram-se no estudo de:

1) a relação entre a produção de leite e o comportamento de amamentação e desempenho produtivo de bezerros puros e cruzados.

2) a modelagem da curva de lactação de vacas de diferentes raças de gado de corte usando os dados de vários experimentos realizados no Centro de Pesquisa Pecuária do Sudeste-EMBRAPA, São Cartos.e 


\section{CAPITULO II REVISÃO DA LITERATURA}

\section{II.1 Raça da Vaca e Produção de Leite}

A escolha de um genótipo de vacas apropriado em termos de tamanho corporal e potencial de produção de leite, tem uma importância adicional nos diferentes sistemas de produção (Sinclair et al, 1998).

A produção de leite varia entre raças bovinas produtoras de came, durante os diferentes estágios da lactação e com o sistema de manejo alimentar.

Em condições de pastejo, Albuquerque et al (1993) observaram produções de leite de $693.45 \pm 30.56 \mathrm{~kg}$ na lactação de vacas pertencentes a várias raças, com produção média diária de $3.33 \pm 0.11 \mathrm{~kg}$. A raça da vaca influenciou significativamente a produção total de leite. A raça Caracu $(1077.76 \mathrm{~kg})$ apresentou a maior média de produção de leite, seguida das raças Nelore $(631.92 \mathrm{~kg})$ e Gir (406.44 kg).

Os resultados obtidos por Alencar et al. (1988) mostram que as vacas Canchim produzem mais leite que as vacas Nelore dos 30 aos 180 dias após o parto (972 vs $655 \mathrm{~kg}$, sendo que a produção de leite aos 210 dias não diferiu em forma significativa. Foi observada uma queda linear significativa com a progressão da lactação em ambas as raças. No entanto, observaram-se maiores peristências nas vacas Nelore em comparação à raça Canchim.

Cruz et al (1997) também encontraram maior produção de leite em 238 dias de lactação nas vacas Canchim, quando compradas com a raça Nelore (1269 vs. $883 \mathrm{~kg}$ ).

Mc Kay et al. (1994) avaliando a produção e composição do leite de vacas $F 1$ e retrocruzas em três momentos da lactação, não encontraram diferenças definitivas dentro de retrocruzas nem entre retrocruzas e $F 1$.

As produções médias ajustadas encontradas por Mallinckrodt et al. (1993) para as raças Hereford e Simmental foram 1090 e $1539 \mathrm{~kg}$ respectivamente, correspondentes à produções diárias de 5.32 e $7.57 \mathrm{~kg}$ de leite/dia. 
Entretanto, Marston et al. (1992) observaram para as raças Angus e Simmental, produções totais de leite de $1454 \pm 36.4$ e $1724 \pm 47.1 \mathrm{~kg}$ respectivamente no total da lactação, enquanto que até o pico de lactação a produção foi de $9.6 \pm 0.3 \mathrm{~kg} /$ dia para Angus e de $11.4 \pm 0.3 \mathrm{~kg} /$ dia para Simmental. $O$ pico foi atingido aos $67 \pm 1.8$ e $80 \pm 3.7$ dias para Angus e Simmental respectivamente.

As conclusões obtidas por Kress et al. (1990) sugerem que vacas cruzadas atingem maiores produções e persistências nas produções de leite em comparação as raças puras.

\section{II.2 Alimentação e Produção de Leite}

A produção total de leite durante a lactação responde positivamente ao aumento da EM para todas as outras raças. A níveis reduzidos de energia disponivel, efeitos negativos nos componentes da reprodução podem ser manifestados. Maior nível energético na dieta pode retardar a aparição do pico de lactação (Jenkins e Ferrel, 1992).

Aparentemente existiria um padrão geral de declínio na produção de leite durante a lactação que seria dependente do regime alimentício (Mondragon et al, 1983).

O gado de corte responde aos incrementos nos níveis de energia da dieta em forma similar ao gado de leite (Jenkins e Ferrel, 1992). $O$ incremento na produção de leite associado ao incremento da energia consumida é um indicativo da eficiência de produção de leite.

Para vacas recebendo dietas que variaram na sua qualidade e nível energético, Miller et al. (1999) observaram amplitude de produção de leite para 25 semanas de lactação de 1200 a 1800 $\mathrm{kg}$ para vacas cruzadas maduras acasaladas com Angus, Hereford, Charolais, Jersey e Simental.

Maiores produções de leite estão associadas com maiores consumos das vacas e ganhos de peso dos bezerros (Fiss e Wilton, 1993).

Num experimento realizado com vacas de varias raças produtoras de carne, aquelas alimentadas com maiores niveis de energia na dieta produziram mais leite comparativamente as de baixa energia na dieta (7.71 vs. $6.74 \mathrm{~kg} / \mathrm{dia})$. As diferenças em produção de leite entre níveis de energia foram menores na primeira que na segunda lactação (0.62 vs. $1.32 \mathrm{~kg} / \mathrm{dia})$ (Sinclair et al., 1998).

Quadros e Lobato (1997), avaliaram a produção de leite de vacas Hereford puras e cruzadas com Charolais, Nelore e Normando em taxas de lotação de 0,6 e 0,8 EV/ha no Rio Grande do Sul. As diferenças entre lotações para produção de leite foram 6.39 e $5.52 \mathrm{~kg} / \mathrm{dia}$ para 0,6 e $0,8 \mathrm{EV} / \mathrm{ha}$ respectivamente. Observou-se efeito da interação tratamento $\times$ raça, destacandose a produção de leite das vacas cruzadas em lotação $0.6 \mathrm{EV} / \mathrm{ha}$, indicando que o maior potencial de produção leiteira pôde se expressar quando a condição nutricional foi mais favorável. 
Os resultados de Sinclair et al. (1998) indicam que todas as raças exceto as continentais movilizam grandes quantidades de reservas corporais para sustentar a produção de leite. Consequentemente as vacas com altos potenciais de crescimento e relativamente baixos potenciais para produção de leite priorizam o crescimento as expensas da produção de leite, enquanto que as vacas com altos potenciais de produção de leite terão suficiente energia para produção de leite e crescimento, desde que seus requerimentos de mantença sejam relativamente baixos.

Segundo van Oijen et al. (1993) as variações na entrada de energia contribuem muito mais às diferenças em eficiência que as variações em saídas dos bezerros para grupos de vacas diferindo em niveis de produção de leite.

\section{II.3 Produção de Leite e Crescimento do Bezerro}

O peso à desmama dos bezerros é um dos fatores mais importantes na determinação dos retornos econômicos nos sistemas de produção de gado de corte. O ganho de peso pré desmama é fortemente influenciado pela produção de leite e a habilidade de amamentação das vacas (Mondragon et al, 1983; Yokoi et al, 1997).

A produção de leite representa importante fonte de variação no ganho de peso de bezerros de vários grupos genéticos principalmente nos três primeiros meses de vida, uma vez que eles dependem exclusivamente do leite materno. Este efeito muitas vezes tem reflexos positivos até a desmama dos bezerros (Alencar et al., 1996). Na medida em que o bezerro cresce, a sua dependência do leite materno diminui, aumentando a sua capacidade de pastar e, consequentemente, reduzindo a quantidade de leite necessária para produzir uma unidade de ganho de peso (Alencar, 1987).

Alencar et al. (1996) demonstraram efeito significativo da produção de leite sobre o ganho de peso durante os três meses de vida dos bezerros dos grupos Canchim e Canchim-Nelore. Possivelmente a produção de leite das vacas da raça Canchim não tenha sido limitante para o desenvolvimento do bezerro no início da lactação, passando a sê-lo a partir do quarto mês. Entretanto, nos animais da raça Nelore a produção de leite da vaca é baixa desde o início da lactação, tornando-se muito pequena nos últimos meses, sendo limitante no inicio e sem importância no final da lactação (Alencar et al., 1996).

Para Alencar (1989) a produção total de leite foi responsável por uma porção significativa da variação no peso à desmama (22.85\% no Canchim e $18.94 \%$ no Nelore) e no ganho em peso do nascimento à desmama (26.20 no Canchim e $20.32 \%$ no Nelore). 
Mallinckrodt et al (1993) conctuiram que a produção de leite influi sobre crescimento pré desmama mas não tem efeito sobre o crescimento pós desmama. Alencar et al. (1992) verificaram que $101.2 \%$ da superioridade à desmama obtida pelos bezerros filhos de vacas de produção média em relação aos filhos de vacas de produção baixa, é mantida até os 12 meses de idade, e que $94.7 \%$ dessa superioridade é mantida até os 18 meses de idade. Da mesma maneira, quando se comparam os bezerros filhos de vacas de alta produção, com os filhos de vacas de baixa produção, 82.3 e $80.8 \%$ da superioridade à desmama é mantida até os 12 e 18 meses de idade, respectivamente. Porém, houve efeito linear altamente significativo indicando incrementos de 5.18 e $4.20 \mathrm{~kg}$ nos pesos dos bezerros aos 12 e 18 meses de idade respectivamente, para cada $\mathrm{kg}$ de leite produzido pela vaca.

No entanto, os resultados publicados por McMorris e Wilton (1986) indicam que a produção de leite não afeta o ganho de peso pré desmama.

Num estudo realizado em 245 vacas da raça Canchim, foi encontrado que quanto mais pesados eram os bezerros, maior era a produção de leite das vacas. Estes resultados sugerem uma maior necessidade ou capacidade de ingerir leite pelo bezerro mais pesado, ou alguma relação entre o peso do bezerro e a produção de hormônios pela vaca (Alencar et al., 1985).

Algumas pesquisas indicam que incrementos na produção de leite das vacas estão associados com maiores pesos ao abate e de carcaça. Miller et al. (1999) não encontraram efeitos significativos da produção de leite na idade ao abate e o peso por idade ao abate. Apesar disto, uma tendência positiva entre produção de leite e peso por idade ao abate estaria indicando que bezerros filhos de vacas de altas produções de leite seriam finalizados com maiores pesos ao abate.

\section{II.4 Produção de Leite e Sexo do bezerro}

Alguns trabalhos se referem à produção de leite das vacas como influenciada pelo sexo do bezerro.

Para Martson et al (1992) o sexo do bezerro apresenta uma pequena relação com a produção de leite nas raças Aberdeen Angus e Simmental. A produção de leite das mães da raça Aberdeen Angus foi superior quando estas amamentavam fêmeas, enquanto que na raça Simmental as mães de machos tiveram uma pequena vantagem.

Alencar et al (1988) indicam que apesar de existir uma tendência de maiores produções de leite para as vacas que amamentam bezerros machos; as diferenças só foram significativas para a produção diária de leite aos 210 dias de lactação. Neste caso as produções médias foram de 2.61 e $1.95 \mathrm{~kg}$ de leite para as vacas com bezerros machos e fêmeas, respectivamente. 
Para Albuquerque et al (1993) embora a produção de leite das vacas tenha sido maior quando estas amamentavam machos $(730.56 \mathrm{~kg})$, do que fêmeas $(680.19 \mathrm{~kg})$, essa diferença não foi estatisticamente significativa.

Nos trabalhos publicados por Alencar et al (1993) e Cruz et al (1997) o sexo do bezerro não influenciou nenhuma das características estudadas. No entanto houve efeito significativo da interação raça*sexo, onde as vacas da raça Canchim que amamentavam bezerros fêmeas produziram $12 \%$ mais leite total em 238 dias de lactação, que as vacas da raça Canchim que amamentavam bezerros machos. Nas vacas da raça Nelore ocorreu 0 inverso, sendo que as vacas que amamentavam bezerros machos $1 / 2$ Canchim $+1 / 2$ Nelore) produziram $19 \%$ mais leite total.

Outros trabalhos publicados no Brasil encontraram diferenças em eficiência de produção ( $\mathrm{kg}$ de bezerro/kg de vaca à desmama do bezerro) entre vacas que amamentaram bezerros machos e fêmeas. Esta diferença ( 0.41 vs. 0.38 machos e fêmeas respectivamente) era esperada, uma vez que não houve efeito da interação grupo genético da vaca*sexo do bezerro e os machos foram mais pesados. Os autores comentam que esta interação pode influenciar a eficiência de produção, se nela for levado em consideração o consumo de energia da vaca. Vacas que aleitam bezerros machos possivelmente apresentam maiores consumos para atender as maiores demandas nutricionais impostas pelos machos, uma vez que aumentam os seus requerimentos de mantença, conforme evidenciado por outros autores (Euclides Filho et al., 1995).

Para Alencar et al (1999) o sexo do bezerro influenciou significativamente os ganhos de peso dos animais da raça Canchim e os pesos aos 12 e 18 meses dos bezerros Nelore. Os machos Nelore foram sempre mais pesados do que as fêmeas, enquanto nos animais Canchim as fêmeas ganharam mais peso da desmama aos 12 meses de idade, e os machos, dos 12 aos 18 meses de idade.

Para Kress et al (1990) o sexo do bezerro interage significativamente com a raça do pai para várias características de crescimento. $O$ sexo do bezerro teve efeito significativo para a produção de leite na lactação avançada, sugerindo que os machos podem influenciar a suas mães a produzir mais leite. Houveram diferenças importantes entre as raças das vacas para os pesos dos bezerros e as produções de leite na lactação avançada.

Em outro trabalho publicado por Kress et al (1996) os machos apresentaram maiores pesos que as fêmeas. Provavelmente essas diferenças poderiam ser devidas ao fato dos bezerros machos estimulariam maiores produções de leite, mas a produção de leite observada para vacas que amamentaram machos e fêmeas não diferiu significativamente. 


\section{Il.5 Comportamento de Amamentação}

A amamentação e o grau de estimulação da úbere recebido via mamadas do bezerro são reguladores importantes da função reprodutiva pós parto em vacas de corte (Day et al, 1987).

O estímulo da amamentação pode suprimir o reinicio da atividade reprodutiva pós parto. Torna-se importante determinar o comportamento de amamentação normal e elucidar os fatores que o afetam, para poder identificar o papel da amamentação na eficiência reprodutiva do gado de corte (Odde et al., 1985).

Muitas influências ambientais (nutrição, clima, geografía, etc.) assim como diferenças genéticas podem afetar a produção de leite e o comportamento de amamentação (freqüência e duração das mamadas). Não entanto, não tem sido encontradas diferenças entre sexos para estas variáveis (Reinhardt e Reinhardt, 1981; Das et al., 2000).

Alguns trabalhos indicam que o comportamento de amamentaçäo varia com o momento da lactação. Com o avanço da lactação, a freqüência de mamadas declina (-0.00382 mamadas $/ \mathrm{kg}$ de leite. Uma relação similar foi observada para minutos totais/24 horas. Em geral, tem sido observado que a duração de cada mamada não varia, mas a freqüência de mamadas declina com o avanço da lactação. Alguns autores afirmam que a magnitude desta mudança depende da produção de leite da vaca. Em contraste, outros indicam que o nivel de produção de leite da vaca, influencia o comportamento do bezerro (Day et al., 1987).

No trabalho publicado por Reinhardt e Reinhardt (1981), o tempo total de mamadas durante 24 horas declina com a idade do bezerro $(r=-0.75)$. O tempo máximo de mamadas foi de 80 minutos para bezerros muito novos, com uma média de 38 minutos de amamentação por dia. Da mesma forma, o número total de mamadas em 24 horas declina significativamente com a idade ( $r=-0.84$ ), atingindo um número médio de 4.8 mamadas/dia.

Das et al. (2000) observaram que em bezerros Zebuinos puros e cruzados, o número médio de vezes que os bezerros mamam por dia decresce com a idade, assim como a duração média de cada mamada.

Por outro lado, o nível estimado da produção de leite parece ser significativamente afetado pelo comportamento do bezerro. Bezerros que mamam vacas menos produtoras de leite, mamam em forma mais freqüente, mas por menos tempo em cada mamada durante as primeiras fases da lactação. $O$ total de minutos mamados foi negativamente associado com o nível de produção de leite (-0.01369 minutos $/ \mathrm{kg}$ de leite durante 205 dias de lactação) até 52 dias de lactação. A duração de cada mamada aumenta com a produção estimada de leite em todos os estágios da lactação $(x=0.001556$ minutos $/ \mathrm{kg}$ de leite) e foi similar entre estágios (Day et al., 1987).

A raça do bezerro pode influenciar o comportamento de amamentação. Das et al. (2000) observaram que o tempo total de amamentação por dia varia com a raça, sendo significativamente 
superior para bezerros Zebu (11.8 $\mathrm{min}$ ) comparados com os bezerros cruzados $(9.4 \pm 0.19 \mathrm{~min})$, e, que decresce significativamente com o incremento da idade dos bezerros de ambos grupos genéticos. Os bezerros Zebu apresentaram durações de cada mamada significativamente superiores aos bezerros cruzados ( 2.8 vs. $2.3 \mathrm{~min}$ ), assim como maiores freqüências de mamadas por dia ( 2.8 vs. 2.2 , respectivamente).

Para Kress et al (1996) os bezerros cruzados são capazes de estimular a suas mães a produzirem mais leite em lactação avançada. Em contraposição, Grings et al. (1996) indicam que o potencial do crescimento do bezerro não afeta a produção de leite nem o consumo das vacas.

Alencar et al (1995) encontraram efeitos significativos do grupo genético do bezerro sobre o número e a duração das mamadas. Os bezerros da raça Canchim mamaram menor número de vezes $(2,2)$, com uma duração média de cada mamada maior $(8.2)$, do que os meio sangue $(2,9$ mamadas/dia e 7,0 minutos/mamada), mas não houve diferença entre o tempo total de duração (18,3 e 20,6 minutos/dia para Canchim e $1 / 2$ Canchim + 1/2 Nelore, respectivamente).

Ribeiro et al. (1991) observaram maiores freqüências de amamentação em bezerros cruzados Angus $x$ Charolais em comparação com os bezerros Angus puros (4 vs 2 vezes/dia).

Existem marcantes diferenças na atividade de amamentação em diferentes horas do dia. Durante a noite são observados menor número de mamadas em comparação com a manhã cedo, pleno dia final da tarde. Em relação as freqüências das mamadas, manhã cedo e final da tarde não diferem entre elas, mas cada uma das duas foram superiores que as freqüências observadas durante 0 dia e a noite. Parece existir uma forte influência dos fatores externos no comportamento de amamentação. Assim como o amanhecer apareceria como um "ligador" das mamadas, o anoitecer apareceria como um "desligador", mostrando no resto do dia um comportamento não consistente (Reinhardt e Reinhardt, 1981).

Para Odde et al. (1985) a maior atividade de amamentação foi observada entre as 5.00 e às 6.00 horas. Outros picos de atividade foram às 10.00 e às 13.00 horas e das 17.00 às 21.00 horas. O peso do bezerro e a produção de leite estiveram associados com o número de mamadas. A equação de regressão para peso do bezerro na incidência de mamadas foi $y=6.42-0.007 x$ $\left(n=371, r^{3}=0.07\right)$. Altas produções de leite e altos pesos de bezerros resultaram em menores números de mamadas. Idade, raça e sexo não afetaram a duração nem a freqüência de mamadas.

\section{II.6 Técnicas para Estimação da Produção de Leite}

As estimativas publicadas da produção de leite dentro de uma dada raça variam de maneira considerável (Mondragon et al., 1983). Muitas destas diferenças são devidas às metodologias utilizadas para estimar a produção de leite. 
Na revisão feita por Williams et al. (1979) são resumidos os principais métodos utilizados para estimar a produção de leite em gado de corte:

a) Canulação da úbere mais injeção de oxitocina.

b) Remoção do leite através de máquina de ordenha ou a mão.

c) Diferença de peso do bezerro antes e depois de mamar ("pesar-mamar-pesar"), após um intervalo de separação da vaca.

Estes procedimentos, particularmente aqueles que controlam o período de amamentação prévio à separação do bezerro, requerem repetições. Algumas destas técnicas são possiveis de serem utilizadas, unicamente com um número baixo de animais, não sendo adaptáveis às condições de campo, onde grandes rebanhos são utilizados (Beal et al., 1990).

Uma análise realizada por Beal et al, (1990) revelou o que 0 tempo que o bezerro permanece separado da sua mãe prévio à ordenha ou amamentação não tem efeito significativo na produção de leite. Este achado é consistente com estudos prévios, os quais indicaram que a produção de leite é menos influenciada pelo intervalo de separação quando este foi de 16 horas, comparativamente a 4 horas.

Os intervalos curtos de tempo entre as mamadas produzem maiores quantidades de leite em 24 horas, em concordância com os resultados obtidos para gado de leite, sendo o leite adicional produzido, devido à liberação mais freqüente de oxitocina (Williams et al, 1979).

Por outro lado, as medições cada 4 horas podem ser menos precisas devido a que quando a produção é multiplicada por 6 horas para ajustar uma base de 24 horas, pode resultar em grandes erros (Williams et al., 1979; Mondragon et al, 1983).

O incremento na pressão da úbere pode ser o fator causante da produção reduzida para intervalos de 16 horas de separação (Williams et al., 1979).

Para Mondragon et al. (1983) os erros padrão foram superiores quando a produção de leite foi obtida pelos métodos de amamentação.

As correlações simples entre duas estimativas de produção de leite são utilizadas para estimar a precisão do método "pesar-mamar-pesar" (Beal et al., 1990). O valor de " $r$ " obtido para as medições com máquina duas vezes consecutivas foi de $0.97(\mathrm{P}<0.001)$, indicando que máquina de ordenha é um procedimento muito apropriado para comparar diferenças em produção de leite entre vacas e ganhos de peso dos bezerros. Por outro lado, a correlação obtida entre o ganho de peso pré desmama e a produção de leite através do método de pesagem do bezerro antes e após a amamentação foi de 0,76 , indicando a menor precisão do método (Beal et al., 1990).

Algumas comparações feitas entre amamentação direta e a máquina encontraram menores produções de leite com máquina que com o bezerro mamando. As estimativas da máquina são de 
esperar menores que as realizadas através da amamentação direta, devido a que o bezerro não remove o leite total (Mondragón et al, 1983).

Beal et al. (1990) concluem que a precisão de máquina de ordenha, a consistência da produção de leite e a forte relação das estimativas da produção de leite com o ganho de peso, são indicativos de que este seria o melhor método para estimar a produção de leite das vacas.

A maioria dos estudos brasileiros foram feitos com base no peso do bezerro, usando duas medidas por dia (Ribeiro et al., 1991;Alencar et al., 1985-1999). Conforme, provavelmente este método determinaria uma subestimativa da produção de leite das vacas de corte.

\section{II.7 Modelagem da Curva de Lactação}

Em gado de leite, o estudo sobre as curvas de lactação contribui para melhor entendimento do sistema de produção e auxilia no planejamento da empresa rural, permitindo a previsão da produção em qualquer estádio da lactação, assim como a identificação antecipada de animais de maior potencial produtivo, e a seleção de machos e fêmeas e a utilização de mais filhas na avaliação de touros (Junqueira et al., 1997).

Vários fatores foram encontrados como afetando as curvas de lactação de gado de leite, entre eles: ano de parto, período de serviço, idade da vaca, duração da lactação, duração do dia, etc. (Durães et al., 1991, Junqueira et al., 1997, Varona et al., 1998).

Muitos métodos tem sido propostos para descrever as curvas de lactação em gado de leite. O mais utilizado na atualidade é o descrito por Wood (1967) onde $Y_{n}=a n b$ e(cn) em que Yn é a produção diária de leite no período do tempo n, e a base dos logaritmos neperianos, a: a produção média no início da lactação, $b$ : a taxa média de ascensão da produção até atingir o pico e c: a taxa média de declínio da produção após o pico (Durães et al., 1991, Junqueira et al., 1997).

A predição das curvas de lactação em gado de corte pode contribuir na determinação de estratégias de manejo e combinações raciais que permitam melhorar a eficiência de produção do complexo vaca/bezerro (Ramirez et al., 1998).

No entanto, algumas limitações tem sido encontradas no uso de este modelo para descrever a lactação através dos controles leiteiros. Para Varona et al. (1998) a principal limitação do modelo proposto por Wood (1967) é a presença de lactações atipicas (valores de b ou c negativos) quando são usados métodos lineares ou não lineares para o cálculo de parâmetros individuais.

Ramirez et al. (1998) discutem a utilização do modelo de Wood linearizado quando este usa como ponderador ao quadrado da produção de leite. Segundo os autores, nas condições nas quais é obtido o modelo de regressão com heterogeneidade de variâncias, ao utilizar este 
ponderador as estimativas serão viciadas não obtendo a condição de homeocedasticidade requerida para supor que os erros são distribuídos normal e independentes.

Uma alternativa proposta por Varona et al. (1998) para a análise de controles leiteiros e 0 uso do esquema hierárquico Bayesiano o qual assume um modelo linear para os parâmetros da curva da lactação. Neste modelo, podem ser incluídos os efeitos sistemáticos e os valores genéticos juntamente com as fontes de variação residuais. Neste trabalho, é confirmado o poder do procedimento em reduzir a influência dos "outliers" provenientes de lactações atípicas. No entanto os autores discutem que a aplicação do esquema Bayesiano para os controles leiteiros está muito condicionada à escolha de curvas de lactação apropriadas.

Recentemente, os modelos de regressão aleatória têm sido aplicados para analisar os controles leiteiros na estimação e predição de parâmetros genéticos. $O$ procedimento permite a predição dos valores genéticos para cada estágio particular da curva de lactação (Varona et al., 1998).

Gengler et al. (1999) destacam o poder dos modelos de regressão aleatória em descrever a estrutura de (co)variância num espaço multivariado de uma maneira infinitamente dimensionada.

Segundo Jamrozik et al. (1997) uma das grandes vantagens do uso da regressão aleatória consiste na análise dos efeitos ambientais de cada controle leiteiro. Os animais podem ser avaliados sobre a base de controles leiteiros podendo ser obtidas curvas de lactação de cada animal e permitindo calcular os valores genéticos das produções parciais dentro da lactação e da persistência

Segundo Meyer (2000) os modelos de regressão aleatória são apropriados para registros repetidos de características que mudam gradativa e continuamente através do tempo, sem requerer de pressuposições confusas no referente à constância das variâncias e correlações.

Muitos autores discutem em relação às estimativas de parâmetros genéticos sendo muito dependentes do modelo utilizado que no modelo de lactação (STRABEL e MISZTAL, 1999, EL FARO et al., 1999).

Kettunen et al. (1998) compararam as estimativas de herdabilidade para controles leiteiros e as correlações genéticas entre os dias individuais obtidas através de dois modelos de regressão aleatória (polinomial com 5 parâmetros logaritmicos e polinomial de quarto ordem ortogonal) e um modelo multivariado, observando um padrão de variação similar em ambos métodos com valores superiores no começo e final da lactação entre 0.40 e 0.58 .

Strabel e Misztal observaram a herdabilidade dos controles leiteiros com valores aproximados entre 0.19 e 0.26 para vacas de primeira e segunda lactação.

Jamrozik e Schaeffe (1997) encontraram os maiores valores de herdabilidade nos primeiros 10 dias da lactação, variando de 0.40 a 0.59 no total dos controles leiteiros analisados. 
Olori et al. (1999) trabaihando comparando vários modelos, observaram que as estimativas da herdabilidade correspondentes ao modelo quadrático variaram de 0.22 a 0.40 , seguindo um padrão de menores valores nas fases iniciais da lactação ( $4^{\mathrm{a}}$ semana) e superiores no final ( $35^{\mathrm{a}}$ semana). No entanto, estas estimativas também foram superiores no final da lactação para todos os modelos testados.

Gengler et al. (1999) observou que em forma similar aos coeficientes da função de (co)variância, uma alta variabilidade nos valores da herdabilidade, com valores inferiores no momento do pico de produção de leite. Segundo os autores a expressão do pico da lactação pode ser uma característica menos herdável em gado de leite devido a que algumas diferenças em produção de leite são mais aleatórias e de difícil predição em comparação aos baixos niveis de produção.

Os valores encontrados por Kettunen et al. (1998) para a herdabilidade através dos dois modelos utilizados na RR mostraram uma tendência similar sendo superiores no começo e final da lactação. As estimativas das herdabilidades foram inferiores nas primeiras etapas da lactação, atingindo o valor mínimo no pico para depois subir e levemente diminuir no final da lactação.

Gengler et al. (1999) observaram efeitos genéticos constantes com correlações positivas e negativas de baixas a moderadas para $o$ intercepto e os efeitos lineares e quadráticos da regressão aleatória.

Strabel e Misztal (1999) observaram correlações genéticas entre a primeira e segunda parição de 0.6 ao começo da lactação, 0.9 na metade e 0.8 no final da lactação.

Shahrbabak (1997), Kettunen et al (1998) e El Faro et al. (1999) observaram que os valores superiores das correlações genéticas foram entre dias consecutivos de controle $(0.90$, 0,81-0,98 e 0.70-1.00, respectivamente), entanto que diminuem com o aumento do intervalo entre controles, podendo se tomar negativas quando este supera os 200 dias.

Gengler et al. (1999) explicam que as baixas correlações genéticas obtidas entre controles distanciados podem ser devidas ao uso de modelos de regressão aleatória em comparação aos multivariados.

Olori et al. (1999) encontraram que para qualquer para de controles leiteiros testados, as correlações genéticas foram consistentemente superiores às ambientais, entanto que ambas declinam com o aumento dos intervalos entre controles. As correlações genéticas obtidas entre a semana 4 e 40 apresentaram em média um valor de 0.50 , sugerindo que a seleção de animais por altas produções em estádios iniciais da lactação pode ter um efeito positivo sobre a produção total de leite.

Shahrbabak (1997) observou correlações genéticas baixas entre os controles realizados nas fases iniciais e finais da lactação em gado de leite, sendo em alguns casos iguais a zero ou 
negativas. Segundo o autor, estes valores são indicativos de baixas persistências na produção de leite após o pico de lactação. 


\section{CAPITULO III}

\section{PRODUÇÃO E LEITE E COMPORTAMENTO DE AMAMENTAÇÃO EM CINCO SISTEMAS DE PRODUÇÃO DE GADO DE CORTE}

Ana Carolina Espasandin ${ }^{1}$, Irineu Umberto Packer ${ }^{2}$, Maurício Mello de Alencar ${ }^{3}$

\section{RESUMO}

Foram estudadas a produção de leite de vacas Nelore e o comportamento de amamentação de bezerros em diferentes sistemas de produção (SIST): NR-Nelore Referência (manejo tradicional); NI-Nelore Intensivo; e três cruzamentos CN-Canchim $\times$ Nelore, AN-Angus $\times$ Nelore e SN-Simental $x$ Nelore, em regime intensivo. Em três momento da lactação (60, 120 e 180 dias após o parto) nos bezerros foram medidas a freqüência e duração das mamadas, e ganho diánio de peso $(\mathrm{Kg} / \mathrm{dia})$. $\mathrm{A}$ produção de leite apresentou efeito significativo do momento da lactação e da interação sistema de produção por momento da lactação. A produção de leite não teve relação direta com 0 comportamento de amamentação nem o ganho de peso dos bezerros dos diferentes sistemas de produção. Condições deficientes de alimentação não resultaram em menores produçōes de leite de vacas Nelore, mas sim em acentuadas perdas de peso durante a estação de monta no sistema NR. O tempo diário de amamentação apresentou quedas significativas no sistema extensivo durante a lactação, enquanto que os sistemas intensivos não mudam ou aumentam os minutos de amamentação por dia. Para as condições nas quais o experimento foi desenvolvido, os bezerros cruzados apresentaram os melhores desempenhos durante a fase pré desmama, em comparação com os sistemas puros.

Palavras chave: comportamento de amamentação, gado de corte, produção de leite

\footnotetext{
'Estudante de Mestrado ESALQ-USP Convênio PEC/PG - Prof. Univ. R. O. del Uruguay

${ }_{2}^{2}$ Professor Titular Depto. De Produção Animal ESALQNUSP - Bolsista CNPq

${ }^{3}$ Pesquisador EMBRAPA-CPPSE - Bolsista CNPq
} 


\begin{abstract}
MILK YIELD AND SUCKLING BEHAVIOUR IN FIVE BEEF CATTLE PRODUCTION SYSTEM
\end{abstract}

Milk yield of Nellore cows and suckling behaviour in calves in different production systems: NRNellore Reference, NI- Intensive Nellore; and three crossbreeding systems CN- Canchim-Nellore, AN-Angus-Nellore and SN-Simmental-Nellore in intensive management, was studied. Measurements for calves were bouts and lenght of suckles, and daily gain ( $\mathrm{Kg} / \mathrm{day})$ in a three moments of lactation (60,120 and 180 days after calving). Moment of lactation and production system by lactation moment interaction was a significant effect in milk yield. Milk yield did not show any relationship with suckling behaviour or daily gain in calves. Extensive grazing conditions did not cause lesser levels in milk yield of Nellore cows althoughthey determined significant weight losses during the breeding season in the NR system. Daily lenght of suckling during lactation phase decreased in the NR system, and sustained or increased in intensive systems. Crossed calves showed higher daily gain and weaning weight than pure bred.

Key Words: beef cattle, milk yield, suckling behaviour 


\section{INTRODUÇÃO}

A produção de leite das vacas é característica importante na pecuária de corte, uma vez que grande parte dos nutrientes ingeridos pelos bezerros nos primeiros meses de vida provem do leite materno. Várias pesquisas demonstram que o leite materno é responsável por uma porção significativa (de 20 a $25 \%$ ) da variação no peso à desmama e no ganho de peso do nascimento à desmama (Alencar, 1989; Albuquerque et al., 1993).

A quantidade de leite produzido por uma vaca de corte varia em função do seu genótipo, e do genótipo do bezerro (Day et al., 1987). O nível de alimentação influencia a produção de leite e a expressão do pico de lactação (Jenkins e Ferrel, 1992). Maiores produções de leite estão associadas com maiores consumos e ganhos de peso dos bezerros (Fiss e Wilton, 1993). Porem, quando as fontes de alimentação são limitadas, as reservas corporais podem ser utilizadas para cobrir requerimentos nutricionais (Jenkins e Ferrel, 1992). Vacas alimentadas com maiores niveis de energia na dieta produzem mais leite que as vacas tratadas com baixa energia na dieta ( 7.71 vs. $6.74 \mathrm{~kg} / \mathrm{dia}$ ) (Sinclair et al., 1998).

Quadros e Lobato (1997) avaliaram a produção de leite de vacas Hereford puras e cruzadas com Charolais, Nelore e Normando em taxas de lotação de 0,6 e 0,8 EV/ha, obtendo diferenças significativas entre lotações para produção de leite, produzindo 6.39 e $5.52 \mathrm{~kg} /$ dia. Observou-se efeito da interação lotação $x$ raça, destacando-se a produção de leite das vacas cruzadas em lotação $0.6 \mathrm{EV} / \mathrm{ha}$, indicando que o maior potencial de produção leiteira pôde se expressar na condição nutricional mais favorável.

Os resultados de Sinclair et al (1998) indicam que a maioria das raças produtoras de carne movilizam grandes quantidades de reservas corporais para sustentar a produção de leite. Consequentemente, as vacas com altos potenciais de crescimento e relativamente baixos potenciais para produção de leite prionizam o crescimento as expensas da produção de leite, enquanto que as vacas com altos potenciais de produção de leite terão suficiente energia para produção de leite e crescimento, sempre que seus requerimentos de mantença sejam relativamente baixos.

Aparentemente existe um padrão geral de declinio na produção de leite durante a lactação que seria dependente do regime alimentício (Mondragon et al, 1983). Nas raças Canchim e Nelore Alencar et al. (1988) observaram uma queda linear da produção de leite com a progressão da lactação.

O ganho de peso pré desmama é fortemente influenciado pela produção de leite e a habilidade de amamentação das vacas (Yokoi et al, 1997: Mondragon et al. 1983). Alguns resultados indicam que o 
potencial de crescimento do bezerro não influencia a produção de leite das vacas. Os altos potenciais de crescimento são compensados com maiores consumos de forragem para satisfazer as demandas nutricionais do crescimento extra, quando comparados com bezerros de menores potenciais de crescimento Grings et al, (1996).

Alguns trabalhos tem apresentado relações entre a produção de leite e o comportamento de amamentação. Influências genéticas e ambientais podem afetar o comportamento de amamentação dos bezerros e a produção de leite das vacas (Day et al., 1987). A raça do bezerro pode influenciar o comportamento de amamentação. Das et al. (2000) observaram que o tempo total de amamentação por dia varia com a raça, sendo significativamente superior para bezerros zebuinos (11,8 minutos) comparados com bezerros cruzados ( 9,4 minutos). Os bezerros zebuinos apresentaram duração de cada mamada significativamente superiores aos bezerros cruzados $(2,8$ minutos vs. 2,3 minutos), assim como maiores freqüências de mamadas por dia (2,8 vs. 2,2, respectivamente). Altas produções de leite e altos pesos de bezerros tem sido associadas com menores números de mamadas (ODDE et al., 1985).

O tempo total de amamentação por dia decresce com o aumento da idade dos bezerros de diferentes grupos genéticos (Das et al., 2000).

Segundo Ribeiro et al. (1991) vacas amamentando bezerros mestiços produziram $29 \%$ mais leite comparativamente aquelas que amamentavam bezerros puros. Alencar et al. (1995) encontraram efeitos significativos do grupo genético do bezerro sobre o número e a duração das mamadas, para bezerros das raças Canchim e meio sangue Canchim-Nelore.

O número total de mamadas declina com o avanço da idade do bezerro (Reinhardt e Reinhardt, 1981), mas a duração de cada mamada não muda (Day et al., 1987).

Encontraram-se tendências de maiores produções de leite em vacas amamentando bezerros machos do que fêmeas, apesar de ser significativa só para a produção de leite diária aos 210 dias de lactação (Alencar et al, 1988). Vacas da raça Canchim amamentando bezerros fêmeas produziram $12 \%$ mais leite total, do que aquelas com bezerros machos, e, nas vacas da raça Nelore ocorreu o inverso, ou seja, as vacas que amamentavam bezerros machos produziram $19 \%$ mais leite total (Cruz et al., 1997). Outras pesquisas não encontraram diferenças entre sexos para o comportamento de amamentação (Reinhardt e Reinhardt, 1981).

O objetivo deste trabalho consiste em avaliar a produção de leite de vacas Nelore amamentando bezerros puros ou cruzados, bem como o crescimento e comportamento dos mesmos durante a fase pré desmama. 


\section{MATERIAL E MÉTODOS}

O trabalho faz parte do Projeto "Estratégias de cruzamentos, práticas de manejo e biotécnicas para intensificação sustentada da produção de carne bovina", Subprojeto "Avaliação de diferentes sistemas de cruzamento entre raças bovinas de corte" do CPPSE (EMBRAPA), que visa comparar, sob diversos aspectos, os seguintes sistemas (SIST): NR-Nelore Referência, NI-Nelore Intensivo e três cruzamentos CN-Canchim $\times$ Nelore, AN-Angus $\times$ Nelore e SN-Simental $\times$ Nelore, em regime intensivo.

O sistema NR simulou condições de manejo tradicional sob pastejo em Brachiaria brizantha cv. Marandu com taxa de lotação de 1 UA/ha. Os sistemas NI, CN, AN e SN foram manejados em pastejo de Panicum maximum com taxas de lotação de 5 UA/ha, incluindo suplementação de vacas e bezerros durante a época da seca.

Nas vacas foram avaliadas a produção de leite aos 60, 120 e 180 dias após o parto (PL.0, $\mathrm{PL}_{120}$ e $\mathrm{PL}_{180}$ ) através da técnica da pesada do bezerro antes e após a mamada; e a variação de peso durante a estação de monta (VP).

Nos bezerros foram medidos os ganhos de peso diários entre 0-60, 60-120 e 120-180 (períodos (MOM) 1, 2 e 3, respectivamente), dias após o parto $\left(G D_{0-60}, G D_{60-120}\right.$ e $\left.G D_{120-180}\right)$, e o peso a desmama (PD).

No dia seguinte a cada determinação da produção de leite (PL) era observado o comportamento de amamentação através do número (NM) e a duração de cada mamada (MinM) das 6.00 às 18,00 hs.

A produção de leite e o comportamento de amamentação, considerados como medidas repetidas no tempo, foram analisados conforme modelo misto:

$Y_{i j k m}=S I S T_{i}+S E X O_{j}+I V_{k}+V a c a(S I S T)_{h(i)}+M O M_{m}+S I S T^{\star} M O M_{(i m)}+e_{i j k l m}$

onde:

$\mathbf{Y}_{\mathrm{ijklm}}$ representa a produção diária de leite $(\mathrm{Kg})$

SIST, representa o efeito fixo do sistema de produção (NR, NI, CN, AN e SN);

SEXO, representa o efeito fixo do sexo do bezerro;

$\mathrm{N}_{\mathbf{k}}$ representa a covariável idade da vaca;

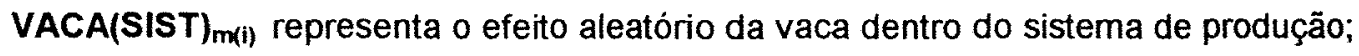

MOM $_{m}$ representa o momento da lacttação $(60,120$ e 180 dias após o parto)

SIST $^{\star}$ MOM $_{(\mathrm{im})}$ representa a interação entre sistema de produção e momento da lactação

$\mathbf{e}_{\mathrm{ijklm}}$ representa o erro padrão 
A persistência da produção de leite foi estudada através da produção final (180 dias) ajustada pela produção inicial (60 dias após o parto) mediante modelo:

$$
P L 180_{i j k l}=S I S T_{i}+S E X O_{j}+I V_{k}+P L 60_{1}+V A C A(S I S T)_{m(i)}+e_{i j k l}
$$

As relações entre as variáveis ganho de peso, produção de leite e comportamento de amamentação foram estudadas através de análises de regressão e correlação.

Os ganhos de peso dos bezerros foram analisados através de modelo similar à produção de leite, contendo além as produções de leite como covariáveis. Os ganhos de peso dos bezerros dos diferentes sistemas de produção foram comparados mediante os contrastes ortogonais:

\section{Puros vs. Cruzados;}

NR vs. NI;

Británicos (AN) vs. Continentais (CN, SN);

Canchim vs. Simental

As análises de variância foram realizadas mediante métodos REML através do procedimento MIXED do programa SAS (1997), usando estimativas de covariância do tipo UN, mediante modelo selecionado pelo critério de Akaike, conforme sugerido para medidas repetidas (Leittell et al., 1996).

Sempre que necessárias foram estimadas as médias ajustadas e comparadas entre si pelo teste $\mathbf{t}$. 


\section{RESULTADOS E DISCUSSÃO}

A produção de leite apresentou efeitos significativo do MOM da lactação $(P<0,001)$ e da interação SIST*MOM $(P<0,02)$, enquanto que o tempo diánio de amamentação apresentou interação SIST*MOM significativo $(P<0,02)$.

Na Tabela 1 são apresentadas as médias ajustadas da produção de leite para cada um dos cinco sistemas de produção estudados, e na Figura 1 as médias são representadas gráficamente.

Tabela 1. Produção de leite nos cinco sistemas de produção em três momentos da lactação

\begin{tabular}{cccccc} 
MOMENTO & NR & NI & CN & AN & SN \\
\hline 60 dias & $4,96 \mathrm{a}$ & $3,91 \mathrm{ab}$ & $3,79 \mathrm{ab}$ & $4,63 \mathrm{ab}$ & $5,69 \mathrm{a}$ \\
120 dias & $4,02 \mathrm{ab}$ & $3,52 \mathrm{ab}$ & $4,49 \mathrm{ab}$ & $3,10 \mathrm{ab}$ & $3,5 \mathrm{ab}$ \\
180 dias & $9,38 \mathrm{ab}$ & $3,51 \mathrm{ab}$ & $3,68 \mathrm{ab}$ & $3,43 \mathrm{ab}$ & $3,26 \mathrm{ab}$
\end{tabular}

Valores seguidos de letras iguais, não diferem em forma significativa $(P<0,05)$

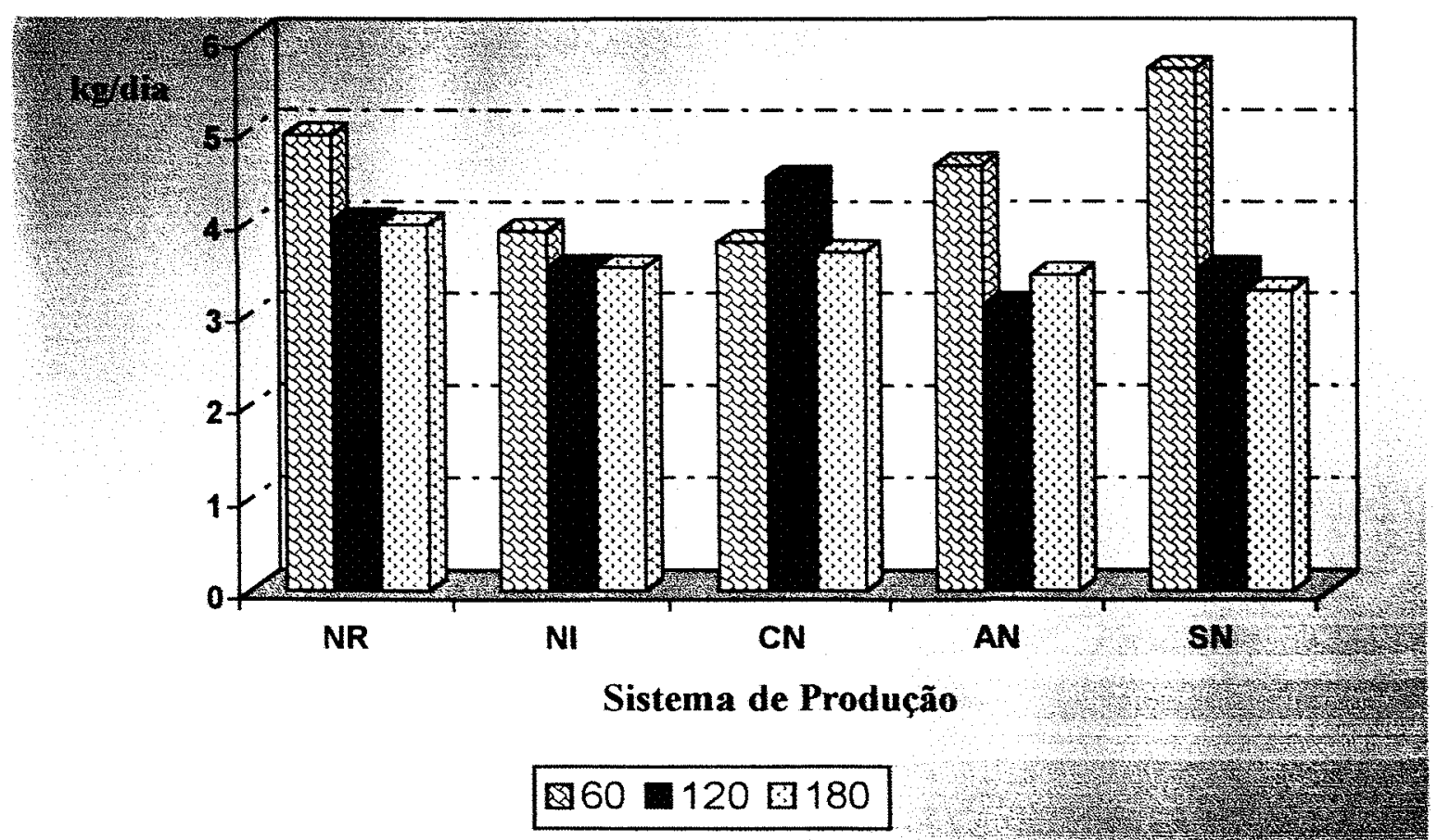

Figura 1. Produção de Leite durante a lactação em cinco sistemas de produção 
A PL decresce em forma apreciável nos sistemas NR, AN e SN com o avanço da lactação, enquanto que para os sistemas NI e CN permanece constante. A diminuição da produção de leite com o avanço da lactação, concorda com os resultados encontrados por Alencar et al. (1988), que observaram queda da produção de leite de modo linear e significativa.

Ao contrário do observado por Quadros e Lobato (1997), a produção de leite não foi superior nos sistemas de produção intensiva.

$A$ análise da persistência da produção de leite $\left(P L_{180}\right)$ apresentou efeitos significativos do sistema de produção $(P<0,02)$ e da interação $S I S T^{*} P L_{60}(P<0.04)$. Somente no sistema NR foi encontrado efeito significativo da produção de leite aos 60 dias após o parto sobre a produção de leite aos 180 dias $(P<0.008)$. Estes resultados acompanham as tendências publicadas por Sinclair et al. (1998), indicando que a vaca Nelore priorizara a produção de leite ainda em condições de alimentação adversas.

Conforme publicado por Jenkins e Ferrel (1992) provavelmente a produção de leite do sistema NR tenha sido mantida mediante mobilização das reservas corporais, podendo ser comprovado através da perda de peso durante a lactação exibida pelas vacas do sistema NR em comparação com os sistemas intensivos ( 80 vs. $20,8,11$ e $11 \mathrm{~kg}$ para NR, NI, CN, AN e SN, respectivamente).

Não foi obsenado efeito do sexo do bezerro para nenhuma das variáveis estudadas, ao contrário dos resultados encontrados Alencar et al. (1988) e Cruz et al (1997).

A produção total de leite foi comparada através dos mesmos contrastes ortogonais que o comportamento de amamentação. Não foram encontradas diferenças significativas entre os grupos comparados, o qual permitiria concluir que o manejo intensivo, assim como o grupo genético do bezerros não influenciaram a produção de leite das vacas Nelore.

Contrariamente ao observado por Reinhardt e Reinhardt (1981), o número de mamadas por dia não apresenta variação durante a lactação, permanecendo com uma média de 2 mamadas por dia. Este comportamento pode ser devido à prática da suplementação de vacas e bezerros, interferindo com o normal comportamento de pastejo e amamentação.

Em contraposição aos resultados de Day et al. (1987), foi observado uma tendência $(P<0.1)$ de declínio no tempo total de duração de cada mamada com o avanço da lactação, acompanhando a redução na produção de leite dos 60 aos 180 dias após o parto (4.6 vs 3.5 $\mathrm{kg} / \mathrm{dia}$, respectivamente, $P<0,0001$ ).

Na tabela 2 são apresentados os tempos de duração de cada mamada para os cinco sistemas de produção. 
Tabela 2. Tempo de duração de cada mamada (minutos) para cinco sistemas de produção

\begin{tabular}{cc}
\hline $\begin{array}{c}\text { Sistema de } \\
\text { Produção }\end{array}$ & $\begin{array}{c}\text { Duração média das mamadas } \\
\text { (minutos) }\end{array}$ \\
\hline NR & $6,33 \mathrm{~b}$ \\
NI & $7,09 \mathrm{ab}$ \\
CN & $6,52 \mathrm{~b}$ \\
AN & $6,82 \mathrm{~b}$ \\
SN & $7,96 \mathrm{a}$
\end{tabular}

Valores seguidos de letras iguais, nåo diferem em forma significativa $(P<0,05)$

Os bezerros $S N$ apresentam maior tempo de duração de cada mamada, seguido dos bezerros do sistema Nelore Intensivo. Em modo similar ao publicado por Ribeiro et al (1991) e Alencar et al. (1995) o grupo genético do bezerro teve efeito significativo sobre o tempo de duração de cada mamada $(P<0.05)$.

Observa-se também, apesar de não significativo, menores durações das mamadas nos bezerros do sistema extensivo, quando comparados aos intensivos.

O tempo diário de amamentação dos bezerros apresentou um efeito significativo para a interação SIST*MOM $(P<0.04)$.

$\mathrm{Na}$ tabela 3 são apresentadas as médias ajustadas para o tempo diário de amamentação nos 5 sistemas de produção, avaliados nos três momentos da lactação, e na Figura 2 as médias são representadas gráficamente.

Tabela 3. Tempo diário de amamentação nos cinco sistemas de produção avaliados

\begin{tabular}{cccccc}
\hline MOMENTO & NR & NI & CN & AN & SN \\
\hline 60 dias & $19,98 \mathrm{a}$ & $14,33 \mathrm{a}$ & $13,51 \mathrm{a}$ & $13,75 \mathrm{a}$ & $13,13 \mathrm{~b}$ \\
120 dias & $14,49 \mathrm{ab}$ & $11,99 \mathrm{a}$ & $17,91 \mathrm{a}$ & $13,51 \mathrm{a}$ & $13,56 \mathrm{~b}$ \\
180 dias & $9,28 \mathrm{~b}$ & $12,65 \mathrm{a}$ & $17,11 \mathrm{a}$ & $14,04 \mathrm{a}$ & $20,05 \mathrm{a}$ \\
\hline
\end{tabular}

Valores seguidos de letras iguais, não diferem em forma significativa $(P<0,05)$ 


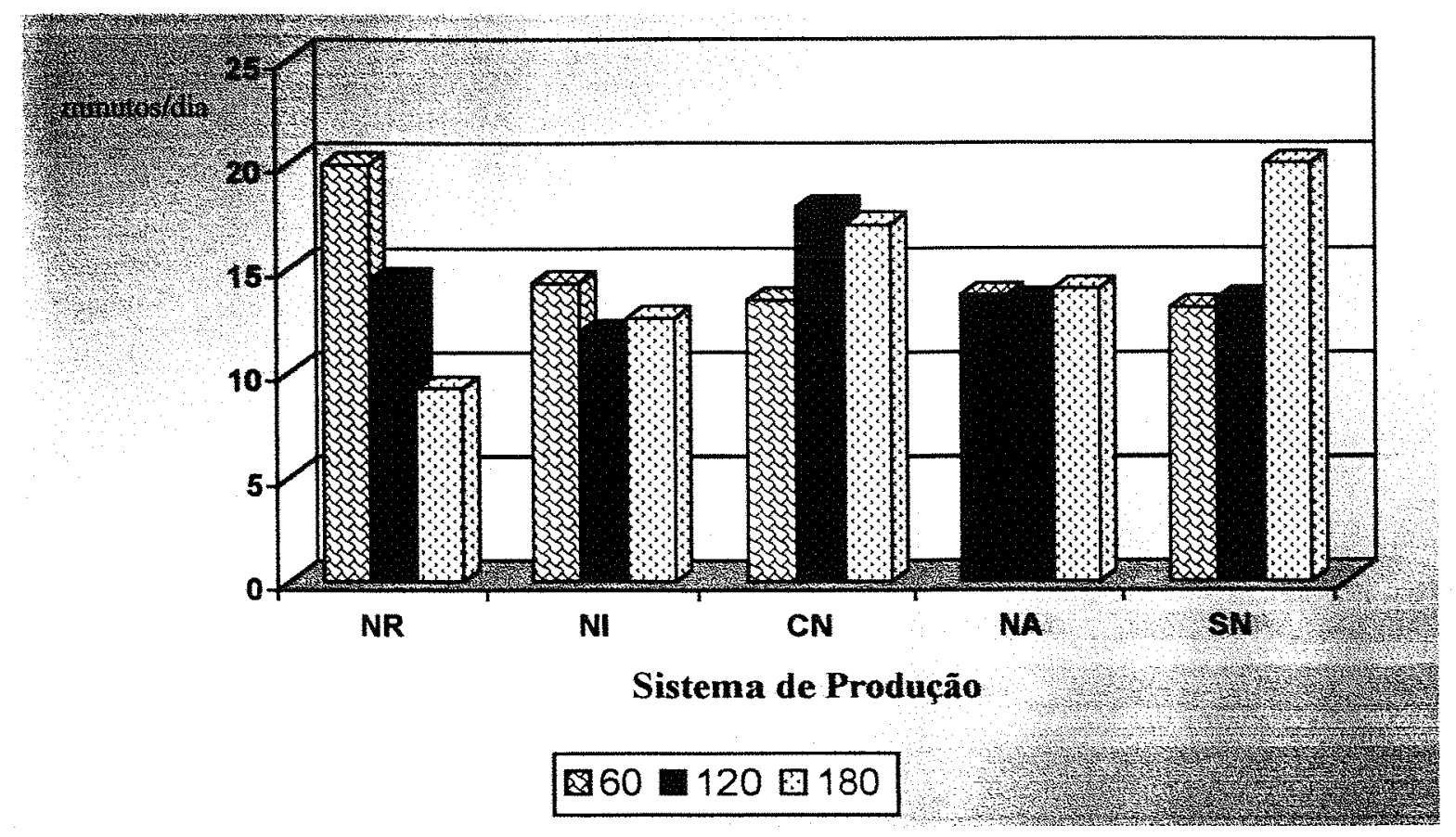

Figura 2. Tempo diário de amamentação (minutos/dia) aos 60, 120 e 180 dias após o parto

O sistema NR mostrou uma tendência diferente às dos outros sistemas. O tempo diário de amamentação decresce com $O$ avanço da lactação (20 vs 9 minutos/dia, $P<0,003$ ). Estas observações concordam com o publicado por DAS et al. (2000), onde o tempo total de amamentação por dia decresce em forma significativa com o avanço da idade dos bezerros. Provavelmente as condições limitantes de alimentação nas quais os animais foram manejados (taxas de lotação de 1,0 UA/ha), tenham influenciado o número e a duração das mamadas dos bezerros, em favor de um aumento do tempo diário de pastejo de vacas e bezerros .

A redução observada no tempo diário de amamentação do sistema NR, não esteve acompanhada por uma redução significativa da produção diária de leite das respectivas vacas (4.96 vs. $3.98 \mathrm{~kg} / \mathrm{dia})$.

Os sistemas de produção com manejos intensivos não apresentaram mudanças significativas, com excepção dos sistemas $\mathrm{CN}$ e $\mathrm{SN}$, os quais aumentam os tempos diários de amamentação (13.5 vs. 17 minutos/dia, e 13.6 vs. 19.3 minutos/dia, $P<0,05$ ).

Com excepção do sistema NR, não foi encontrado um declínio no tempo total de amamentação por dia, ao contrário dos resultados de Das et al. (2000). Este comportamento pode ter sido devido a interferências produzidas pela prática da suplementação de vacas e bezerros nos sistemas intensivos ( $N$, CN, AN e SN). A suplementação provavelmente reduziu o tempo de amamentação nas primeiras fases da lactação. 
Não foi encontrada uma relação entre número e duração das mamadas e produção de leite, diferentemente do observado por Odde et al. (1985), onde as maiores produções de leite estiveram associadas com menores números de mamadas por dia.

Conforme observado para produção de leite, também não foram registradas diferenças entre sexos em relação aos minutos de amamentação por dia, concordando com o publicado por Reinhardt e Reinhardt (1981).

A produção de leite não apresentou relações significativas com as variáveis do comportamento de amamentação dos bezerros. No entanto, foram encontradas algumas correlações significativas mas com coeficientes de determinação baixos (0,20-0,22).

Os ganhos de peso dos bezerros (GD0-60, GD60-120, GD120-180) não estiveram relacionados nem com a produção de leite nem com a atividade de amamentação dos bezerros. Estes resultados não permitem comprovar a forte influência da produção de leite e a habilidade de amamentação sobre o ganho de peso pré-desmama publicada em inúmeros trabalhos (Mondragon et al, 1983; Yokoi et al, 1997).

$\mathrm{Na}$ tabela 4 são apresentadas as médias ajustadas para os ganhos de peso e pesos à desmama dos bezerros dos diferentes sistemas estudados.

Tabela 4. Ganhos diårios pré desmama e pesos à desmama de bezerros puros e cruzados

\begin{tabular}{ccccc}
\hline Sistema & $\begin{array}{c}\text { GD0-60 } \\
(\mathrm{kg} / \mathrm{dia})\end{array}$ & $\begin{array}{c}\text { GD60-120 } \\
(\mathrm{kg} / \mathrm{dia})\end{array}$ & $\begin{array}{c}\text { GD120-180 } \\
(\mathrm{kg} / \mathrm{dia})\end{array}$ & $\begin{array}{c}\text { PD } \\
(\mathrm{kg})\end{array}$ \\
\hline NR & $0,72 \mathrm{~b}$ & $0,57 \mathrm{c}$ & $0,45 \mathrm{c}$ & $136 \mathrm{c}$ \\
$\mathrm{NI}$ & $0,76 \mathrm{ab}$ & $0,70 \mathrm{~b}$ & $0,65 \mathrm{~b}$ & $161 \mathrm{~b}$ \\
$\mathrm{CN}$ & $0,83 \mathrm{ab}$ & $0,75 \mathrm{ab}$ & $0,80 \mathrm{ab}$ & $172 \mathrm{~b}$ \\
$\mathrm{AN}$ & $0,84 \mathrm{a}$ & $0,84 \mathrm{a}$ & $0,85 \mathrm{a}$ & $189 \mathrm{a}$ \\
SN & $0,85 \mathrm{a}$ & $0,80 \mathrm{ab}$ & $0,83 \mathrm{a}$ & $188 \mathrm{a}$ \\
\hline
\end{tabular}

Valores seguido de letras iguais, nåo diferem em forma significativa $(P<0,05)$

Não foi observada a dependência exclusiva do leite matemo nas primeiras etapas da lactação conforme o encontrado por Alencar (1989), uma vez que as maiores produções de leite nem sempre foram acompanhadas dos maiores ganhos de peso dos bezerros.

O grupo NR apresentou os menores ganhos de peso durante toda fase pré desmama $(0,72$; 0,57 e $0,45 \mathrm{~kg} /$ dia nos periodos 1,2 e 3 , respectivamente), enquanto que os grupos AN e SN apresentaram os maiores ganhos de peso para os mesmos períodos $(0,84-0,84-0,85$ e $0,85-0,80$ 0,83 , respectivamente). 
Os menores ganhos do sistema NR podem ser explicados pelas condições diferentes de alimentação as quais foram submetidos. É evidente que a pastagem oferecida aos sistemas NI, CN, AN e SN, assim como a suplementação, favoreceu maiores ganhos diários. Isto é evidenciado pelo ganho de peso realizado pelos bezerros Nelore quando manejados em condições intensivas. No entanto, também é evidenciada uma superioridade dos bezerros cruzados.

Os grupos $\mathrm{NI}$ e CN mostraram desempenhos intermediários $(0,76-0,70-0,75$ e $0,83-0,75-$ 0,80 , respectivamente). Os ganhos de peso superiores dos bezerros cruzados, em relação aos dos grupos puros está de acordo com o publicado por Alencar (1997).

O sistema de manejo tradicional seguramente comprometeu o desenvolvimento nomal dos bezerros e vacas, observando-se perdas de peso comparativamente superiores nas vacas manejadas em condiçōes extensivas, assim como pesos à desmama significativamente menores (136c vs. 161b, 172b, 189a e 188a, para NI, CN, AN e SN respectivamente).

Os diferentes sistemas de produção e cruzamento foram comparados através de contrastes ortogonais os quais demonstraram nítida superioridade dos sistemas de manejo intensivo em relação ao sistema NR, durante toda a fase pré desmama $(P<0,0001)$.

Os pesos à desmama dos bezerros cruzados com raças Européias superaram de forma significativa os pesos dos puros, independente do plano de alimentação e $(136,161 \mathrm{~kg}$ para NR, NI vs. 189 e $188 \mathrm{~kg}$ para AN e SN, respectivamente), ao passo que o desempenho do sistema CN foi intermediário entre os anteriores. O crescimento dos bezerros do grupo $\mathrm{NI}$ superou o dos NR, porém foi inferior aos cruzados, demostrando que a melhora no ambiente não foi suficiente para igualar o desempenho dos bezerros cruzados.

De acordo ao publicado por Grings et al. (1996) os maiores ganhos de peso obtidos pelos bezerros cruzados possivelmente foram acompanhados de maiores requerimentos nutricionais Provavelmente estes requerimentos tenham sido compensados com maiores ingestões de forragem e suplemento, devido a que as vacas que amamentaram bezerros cruzados não foram sempre as que produziram mais $\mathrm{kg}$ de leite. 


\section{CONCLUSÕES}

A produção de leite apresentou efeito significativo do momento da lactação e da interação sistema de produção por momento da lactação.

A produção de leite durante a fase pré desmama não teve relação direta com o comportamento de amamentação nem o ganho de peso dos bezerros dos diferentes sistemas de produção.

Condições deficientes de alimentação não resultaram em menores produções de leite de vacas Nelore, mas sim em acentuadas perdas de peso.

O tempo diário de amamentação apresentou quedas significativas no sistema extensivo durante a lactação, enquanto que os sistemas intensivos não mudam ou aumentam os minutos de amamentação por dia.

Para as condições nas quais o experimento foi desenvolvido, os bezerros cruzados apresentaram os melhores desempenhos durante a fase pré desmama, em comparação com os sistemas puros. 


\section{REFERÊNCIAS BIBLIOGRÁFICAS}

ALENCAR, M.M.; RUZZA, F.J.; PORTO, E.J.S. Desempenho produtivo de fêmeas das raças Canchim e Nelore. III. produção de leite. Revista da Sociedade Brasileira de Zootec., v. 17, n. 4, p. 317-328, 1988.

ALENCAR, M.M., 1989. Relação entre produção de leite da vaca e desempenho do bezerro nas raças Canchim e Nelore. Revista Sociedade Brasileira de Zootecnia, v. 18, n. 2, p.:146156.

ALENCAR, M.M.; CRUZ, G.M. da; TULLIO, R.R.; CORREA, L.A. Características da amamentação de bezerros da raça Canchim e cruzados Canchim x Nelore. Revista da Sociedade Brasileira de Zootecnia, v. 24, n. 5, p.706-714, 1995.

ALENCAR, M.M., BARBOSA, P.F., TULLIO, et al., 1995. Peso à desmama de bezerros da raça Nelore e cruzados Canchim $x$ Nelore e Marchigiana $x$ Nelore. Revista da Sociedade Brasileira de Zootecnia, v. 24, n. 6, p. 917-925.

ALENCAR, M.M., 1997. Los cruzamentos para la producción de carne bovina. In: CONGRESO INTERNACIONAL DE TRANSFERENCIA DE TECNOLOGIA AGROPECUARIA, 1997, Asunción. Anais, Asunción: CEA, 1997, p. 111-122.

ALBUQUERQUE, L.G. de; ELER, J.P.; COSTA, M.R.P. da; SOUZA, R.C., 1993. Produção de Leite e desempenho do Bezerro na fase de Aleitamento em três raças bovinas de corte. Revista da Sociedade Brasileira de Zootecnia, v. 22, n. 5 , p. 745-754.

CRUZ, G.M., ALENCAR, M.M., TULLIO, R.R. Produção de leite de vacas das raças Canchim e Nelore. Revista da Sociedade Brasileira de Zootecnia, v. 26, n. 5, p. 887-893, 1997.

DAS, S.M.; REDBO, I.; WIKTORSSON, H. Effect of age of calf on suckling behaviour and other behavioural activities of Zebu and crossbred calves during restricted suckling periods. Applied Animal Behaviour Science, v. 67, n. 1-2, p. 47-57, 2000. 
DAY, M.L.; IMAKAWA, K.; CLUTTER, A.C.; WOLFE, P.L.; ZALESKY, D.D.; NIELSEN, M.K.; KINDER, J.E. Suckling Behavior of Calves with Dams varying in Milk Production. Joumal of Animal Science, v. 65, p. 1207-1212, 1987.

FISS, C.F.; WILTON, J.W. Contribution of Breed, Cow Weight, and Milk Yield to the Preweanning, Feedlot and Carcass Traits of Calves in Three Beef Breeding Systems. Joumal of Animal Science, v. 71, p. 2874-2884, 1993.

GRINGS, E.E.; SHORT, R.E.; MCNEIL, M.D.; HAFERAMP, M.R.; ADAMS. D.C., 1996. Efficiency of production in cattle of two growth potencials on northorn great plains rangelands during spring-summer grazing. Journal of Animal Science, v. 74, p. 2317-2326.

JENKINS, T.G.; FERREL, C.L. Lactation Characteristics of Nine Breeds of Cattle Fed Various Quantities of Dietary Energy. Journal of Animal Science, v. 70, p. 1652-1660, 1992.

JOHNSTON, D.J.; THOMPSON, J.M.; HAMMOND, K. 1995. Additive and nonadditive differences in milk production of 2 year old Devon, Hereford and reciprocal cross heifers. Livestock Production Science, v. 41, p. 105-110.

LEITTELL, R.C.; MILLIKEN, G.A.; STROUP, W. W.; WOLFINGER, R.D. SAS System for Mixed Models. Cary: SAS Institute, 1996, 633 p.

MONDRAGON, I.; WILTON, J.W.; ALLEN, O.B.; SONG, H. Stage of Lactation Effects, Repeteabilities and Influences on Weaning Weights of Yield and Composition of Milk in Beef Cattle. Canadian Journal of Animal Science, v. 63, p. 751-761, 1983.

ODDE, K.G.; KIRACOFE, G.H.; SCHALLES, R.R. Suckling Behavior in Range Beef Calves. Journal of Animal Science, v. 61, n. 2 , p. 307-309, 1985.

RIBEIRO, E.L.A.; RESTLE, J.; PIRES, C.C., 1991. Produção e composição do leite em vacas Charolês e Aberdeen Angus amamentando terneiros puros ou mestiços. Pesq. Agropec. Brasileira de, v. 26, n. 8, p. 1267-1273.

SAS, 1997. Statistical Analysis System User's Guide: Stat, Version 6.12 Cary:SAS Institute. 
SINCLAIR, K.D.; YILDIZ, S.; QUINTANS, G.; BROADBENT, P.J. Annual energy intake and the performance of beef cows differing in body size and milk potential. Animal Science, v. 66, p. 643-655, 1998.

YOKOI, N.; MORIYA, K.; SASAKI, Y. A mesure for predicting genetic merit for milking and nursing ability. Animal Science, v. 65, p. 39-43, 1997. 


\section{CAPITULO IV}

\section{ESTIMATIVAS DE PARÂMETROS GENÉTICOS DA PRODUÇÃO DE LETTE EM GADO DE CORTE ATRAVÉS DE MODELOS DE REGRESSÃO ALEATÓRIA}

Ana Carolina Espasandin ${ }^{1}$, Irineu Umberto Packer ${ }^{2}$, Maurício Mello de Alencar ${ }^{3}$, Claudio Manuel Rodrigues de $\mathrm{Melo}^{4}$

\section{RESUMO}

Foram estimados parâmetros genéticos para a produção de leite de vacas de corte através da análise de controles individuais de produção (CIP) usando modelos de regressão aleatória. As análises da produção de leite foram realizadas ajustando polinômio de Legendre ( $\left.2^{\circ} \mathrm{grau}\right)$. Foram considerados como efeitos fixos: grupo contemporâneo (ano-mês do CIP), grupo genético da vaca e do bezerro, e as covariáveis peso vivo das vacas e bezerros e como aleatónios o efeito genético aditivo de animal, e 0 ambiente permanente e temporário. Foram estimadas as herdabilidades e correlações genéticas, ambientais e fenotípicas da produção de leite para cada dia de controle individual de produção. As estimativas foram obtidas por máxima verossimilhança restrita usando o programa DXMRR. As herdabilidades para os diferentes controles leiteiros apresentaram valores levemente superiores no início e claramente maiores no final da lactação. A magnitude das estimativas de herdabilidade neste trabalho $(0,23-0,41)$ encontra-se dentro do observado nos trabalhos publicados para gado de leite. As variâncias genéticas aditivas foram inferiores no começo e aumentaram no final da lactação. Conforme esperado e em concordância com os trabalhos revisados as correlações genéticas apresentam valores altos e positivos entre controles sucessivos $(0,98-1,0)$, diminuindo até valores negativos quando os intervalos entre controles superaram os 200 dias.

\footnotetext{
${ }_{1}^{1}$ Estudante Mestrado ESALQ/USP-Convênio PEC-PG. Prof. Univ. de la. R.O. del Uruguay

${ }^{2}$ Professor Depto. Produção Animal ESALQ/USP - Bolsista CNPq

${ }^{3}$ Pesquisador EMBRAPA-CPPSE, São Carlos - Bolsista CNPq

${ }^{4}$ Estudante Doutorado ESALQ/USP - Bolsista FAPESP
} 


\title{
ABSTRACT \\ ESTIMATIVAS DE PARÂMETROS GENÉTICOS DA PRODUÇÃO DE LEITE EM GADO DE CORTE ATRAVÉS DE MODELOS DE REGRESSÃO ALEATÓRIA
}

\begin{abstract}
Genetic parameters for milk yield of beef cows were estimated by test days analysis with random regression models. The analysis for milk production were made using order two Legendre's polynomial. Contemporary group (year-month of test day) and genetic group of cow and calf were considered as fixed effects; live weight of cows and calves were analyzed as covariates, and additive genetic effect of animals and permanent and temporaryenvironmental effects were considered as random effects. Heritability and genetic, phenotipic and environmental correlations of milk yield with each test day were estimated. Estimates were obtained by maximum restricted likelihood using DxMRR program (Meyer, 1998). Heritabilities for milk yield in test day showed slightly higer values at the beginning and significantly higher values at the end of the lactation period. Estimatives of heritability found in this study $(0,23-0,41)$ are similar to those reported in publications for dairy cattle. Additive genetic variances were lower at the beginning and higher at the end of the lactation period. As expected and in agreement with previous literature, genetic correlation showed high and positive values between subsequents tst days $(0,98-1,0)$, decresing till negative values when intervals between test days were higher than 200 days.
\end{abstract}




\section{INTRODUÇÃO}

$\mathrm{Na}$ literatura existem muito poucas estimativas dos parâmetros genéticos para a produção de leite em bovinos de corte, apesar de ser uma característica importante para a produtividade do sistema.

Em gado de leite, o estudo sobre as curvas de lactação contribui para melhor entendimento do sistema de produção e auxilia no planejamento da empresa rural, permitindo a previsão da produção em qualquer estádio da lactação, auxiliando na identificação antecipada de animais de maior potencial produtivo, e a seleção de machos e fêmeas e a utilização de mais filhas na avaliação de touros (Junqueira et al., 1997). Vários fatores afetam as curvas de lactação de gado de leite, entre eles: ano de parto, período de serviço, idade da vaca, duração da lactação, duração do dia, etc (Durães et al., 1991, Junqueira et al., 1997, Varona et al., 1998).

Muitas equações tem sido propostas para descrever a curva de lactação em gado de leite. A mais utilizada na atualidade é a descrita por Wood (1967) onde $Y_{n=a n^{b}} e^{f(n)}$ em que $Y n$ é a produção diária de leite no período do tempo $n$, e: a base dos logaritmos neperianos, a: a produção média no início da lactação, b: a taxa média de ascensão da produção até atingir o pico e c: a taxa média de declínio da produção após o pico (Durães et al., 1991, Junqueira et al., 1997).

A predição das curvas de lactação em gado de corte pode contribuir na determinação de estratégias de manejo e na escolha das combinações raciais que permitam melhorar a eficiência de produção do complexo vaca/bezerro (Ramírez et al., 1998).

No entanto, algumas limitações tem sido encontradas no uso de este modelo para descrever a lactação através dos controles leiteiros. Para Varona et al. (1998) a principal limitação do modelo proposto por Wood (1967) é a presença de lactaçöes atipicas (valores de b ou c negativos) quando são usados métodos lineares ou não lineares para o cálculo de parâmetros individuais.

A produção de leite avaliada em vánios controles individuais de produção (CIP) sucessivos na mesma vaca constitui um exemplo típico de medidas repetidas no tempo. Para tais casos, os modelos de regressão aleatória tem sido recomendados para analisar os controles individuais de produção na estimação e predição de parâmetros genéticos. O procedimento permite a predição dos valores genéticos para cada ponto particular da curva de lactação (Varona et al., 1998).

Segundo Jamrozik et al. (1997) uma das grandes vantagens do uso da regressão aleatória consiste na análise dos efeitos ambientais de cada controle leiteiro. Os animais podem ser avaliados sobre a base de controles leiteiros podendo ser obtidas curvas de lactação de cada 
animal e permitindo calcular os valores genéticos das produções parciais dentro da lactação. Gengler et al. (1999) destacam o poder dos modelos de regressão aleatória em descrever a estrutura de (co)variância num espaço multivariado de uma maneira infinitamente dimensionada. Segundo Meyer (2000) os modelos de regressão aleatória são apropriados para registros repetidos de características que mudam gradativa e continuamente através do tempo, sem requerer de pressuposições no referente à constância das variâncias e correlações.

Kettunen et al. (1998) compararam as estimativas de herdabilidade para controles leiteiros e as correlações genéticas entre os dias individuais obtidas através de dois modelos de regressão aleatória (polinomial com 5 parâmetros logarítmicos e polinomial de quarta ordem ortogonal) e um modelo multivariado, observando um padrão de variação similar em ambos métodos com valores superiores no começo e final da lactação entre 0,40 e 0,58.

Vários autores verificam que as estimativas dos parâmetros genéticos das curvas são dependentes do modelo utilizado para descrever a lactação (Strabel e Misztal, 1999, El Faro et al., 1999).

Strabel e Misztal (1999) estimaram as herdabilidades dos controles leiteiros obtendo valores entre 0,19 e 0,26 para vacas de primeira e segunda lactação.

Jamrozik e Schaeffer (1997) encontraram as maiores estimativas de herdabilidade nos primeiros 10 dias da lactação, variando de 0,40 a 0,59 no total dos controles leiteiros analisados.

Olori et al. (1999) comparando vários modelos, observaram que as estimativas da herdabilidade correspondentes ao polinômio de Legendre de ordem três variaram de 0,22 a 0,40, sendo as estimativas inferiores na fase inicial da lactação ( $4^{a}$ semana) e superiores no final da lactação ( $35^{a}$ semana). No entanto, estas estimativas também foram superiores no final da lactação para todos os modelos testados.

Gengler et al. (1999) obsenaram que de forma similar aos coeficientes da função de (co)variância, uma atta variabilidade nos valores da herdabilidade, com valores inferiores no momento do pico de produção de leite.

As estimativas encontrados por Kettunen et al. (1998) para a herdabilidade através de dois modelos de regressão aleatória mostraram tendência similar sendo superiores no começo e final da lactação. As estimativas das herdabilidades foram inferiores no inicio da lactação, atingindo o valor mínimo no pico para depois subir e levemente diminuir no final da lactação.

Strabel e Misztal (1999) observaram correlações genéticas entre o primeiro e segundo parto de 0,6 no início, 0,9 no meio e 0,8 no final da lactação.

Shahrbabak (1997), Kettunen et al (1998) e El Faro et al. (1999) observaram que as estimativas das correlações genéticas foram superiores para os controles individuais de produção consecutivos $(0,90,0,81-0,98$ e $0,70-1,00$, respectivamente), entanto que diminuem com 0 
aumento do intervalo entre controles, podendo se tornar negativas quando este supera os 200 dias.

Olori et al. (1999) encontraram que para qualquer par de controles individuais de produção, as correlações genéticas foram consistentemente superiores às ambientais, sendo que ambas declinam com o aumento dos intervalos entre controles. As correlações genéticas obtidas entre a quarta e a $40^{\mathrm{a}}$ semana apresentaram em média um valor de 0.50 , sugerindo que a seleção de animais por altas produções em estádios iniciais da lactação pode ter um efeito positivo sobre a produção total de leite.

Shahrbabak (1997) observou correlações genéticas baixas entre os controles realizados no inicio e final da lactação em gado de leite, sendo em alguns casos iguais a zero ou negativas. Segundo o autor, estes valores são indicativos de baixas persistências na produção de leite após o pico de lactação.

O objetivo deste trabalho consiste na estimação de parâmetros genéticos e fenotípicos para a produção de leite de vacas de corte, através do estudo de controles individuais de produção usando um modelo de regressão aleatória. 


\section{MATERIAL E MÉTODOS}

O estudo analisou 1427 controles individuais de produção de um total de 251 vacas das raças Nelore, Canchim e $1 / 2$ sangue Canchim/Nelore, provenientes de experimentos desenvolvidos na fazenda Canchim, do Centro de Pesquisa Pecuária do Sudeste, EMBRAPA-São Carlos. As produções de leite foram coletadas nos anos 1983, 1984, 1985, 1989, 1990, 1991, 1998 e 1999, e estimadas através do método da pesagem dos bezerros antes e após mamarem nas vacas.

As lactações apresentaram controles individuais de produção (CIP) mensais para os anos 83-84-85, semanais para 89-90-91, e bimensais para os anos 98 e 99, respectivamente.

As análises da produção de leite foram realizadas através de um modelo de regressão aleatória unicarácter.

Foram considerados como efeitos fixos (F): grupo contemporâneo (ano-mês do controle individual de produçāo, 54 níveis), grupo genético da vaca ( 3 níveis) e do bezerro ( 6 níveis); como covariáveis: peso vivo de vacas e bezerros (em termos linear e quadrático) e como efeitos aleatórios: efeito genético aditivo do animal, efeito de ambiente permanente e de ambiente temporário, e o efeito residual.

A variável de resposta ( $\boldsymbol{y}_{\mathrm{ij}}$, produção de leite do animal i no controle j) é descrita por:

$$
y_{i j}=F+\sum_{m=0}^{K_{A-1}} \operatorname{\alpha am} \phi_{m}\left(t_{i j}\right)+\sum_{m=0}^{K P-1} \delta_{m} \phi_{m}\left(t_{i j}\right)+e_{i j}
$$

onde $F$ representa o conjunto de efeitos fixos, $\alpha_{i m}$ e $\delta_{i m}$ representam os m-ésimos regressores aleatórios genético-aditivos e de ambiente permanente para cada animal; $K_{A}$ e $K_{p}$ são as ordens dos polinômios para ajustar os regressores, respectivamente.

Matricialmente o modelo pode ser descrito por:

$$
y=x_{b}+z_{1 A}+z_{2 p}+e
$$

onde,

y: é o vetor dos $\mathrm{N}$ controles individuais de produção, medido em ND animais;

b: é o vetor dos efeitos fixos (grupo contemporâneo, grupo genético da vaca e do bezerro, peso vivo da vaca e do bezerro);

a: é o vetor de regressores aleatórios genético aditivo com $K_{A} * N A$ coeficientes;

$p$ : é o vetor de regressores aleatórios de ambiente permanente com $K_{p} * N D$ coeficientes; 
e: é o vetor dos $\mathrm{N}$ resíduos;

$X, Z_{1}$ e $Z_{2}$ são as matrizes de incidências para os efeitos considerados;

$K_{A}$ é a matriz de coeficientes para uma função de covariância genética aditiva $F A, K_{P}$ é a matriz de coeficientes para uma função de covariância de ambiente permanente FP.

No presente estudo a curva de lactação foi descrita através de um polinômio de $2^{\circ}$ grau, para as regressões fixas e aleatórias. Assim (co)variâncias genética aditiva, de ambiente permanente e fixas foram modeladas com um polinômio de mesma ordem, sendo $K_{A=K} K_{p=3}$.

O número de medidas de erro foram sete, assumindo que a variância residual era constante dentro, mas, diferente entre as seguintes classes de controles individuais de produção: $\leq 30,31-60,61-90,91-120,121-150,151-180,>181$ dias após o parto. Na tabela 1 são apresentados 0 número de controles individuais de produção leiteira pertencentes a cada classe definida.

Tabela 1. Número de controles individuais de produção de leite por classe definida

\begin{tabular}{ccc}
\hline Classe (dia do controle) & Número de Registros & Porcentagem (\%) \\
\hline$\leq 30$ & 204 & 14.3 \\
$31-60$ & 289 & 20.3 \\
$61-90$ & 187 & 13.1 \\
$91-120$ & 220 & 15.4 \\
$121-150$ & 150 & 10.5 \\
$151-180$ & 196 & 13.7 \\
$>180$ & 181 & 12.7 \\
\hline
\end{tabular}

Foram estimados os valores de herdabilidade da producão de leite para cada dia de controle individual de produção, assim como as correlações genetiças e ambientais As estimativas foram obtidas por máxima verossimilhança restrita usando o programa DXMRR (Meyer, 1998), pertencente ao pacote DFREML (Derivative Free Restricted Maximum Likelihood, Meyer, 1998). 


\section{RESULTADOS E DISCUSSÃO}

$\mathrm{Na}$ Tabela 2 são apresentadas as estimativas das covariâncias genéticas para os coeficientes de regressão aleatória, assim como as covariâncias dos efeitos permanentes de ambiente e as variâncias ambientais para a produção de leite.

Tabela 2. Estimativas de covariâncias genéticas para os coeficientes de regressão aleatória, e variâncias de ambiente permanente para produção de leite

\begin{tabular}{ccccc}
\hline Parâmetro & \multicolumn{3}{c}{$\begin{array}{c}\text { Produção de Leite } \\
(\mathrm{kg})\end{array}$} & $\begin{array}{c}\text { Variância } \\
\text { Residual }\end{array}$ \\
\hline$\alpha_{0}$ & $\alpha_{0}$ & 0,477 & $\sigma^{2} \mathrm{e}_{1}$ & 1,19 \\
$\alpha_{0}$ & $\alpha_{1}$ & 0,108 & $\sigma^{2} \mathrm{e}_{2}$ & 1,57 \\
$\alpha_{0}$ & $\alpha_{2}$ & $-0,40$ & $\sigma^{2} \mathrm{e}_{3}$ & 1,81 \\
& & & $\sigma^{2} \mathrm{e}_{4}$ & 1,61 \\
$\alpha_{1}$ & $\alpha_{1}$ & 0,318 & $\sigma^{2} \mathrm{e}_{5}$ & 1,39 \\
$\alpha_{1}$ & $\alpha_{2}$ & 0,053 & $\sigma^{2} \mathrm{e}_{6}$ & 1,53 \\
& & & $\sigma^{2} \mathrm{e}_{7}$ & 0,87 \\
$\alpha_{2}$ & $\alpha_{2}$ & 0,045 & & \\
& & & & \\
$\delta_{0}$ & $\delta_{0}$ & 0,409 & & \\
$\delta_{0}$ & $\delta_{1}$ & 0,043 & & \\
$\delta_{0}$ & $\delta_{2}$ & 0,060 & & \\
& & & & \\
$\delta_{1}$ & $\delta_{1}$ & 0,021 & & \\
$\delta_{1}$ & $\delta_{2}$ & 0,004 & & \\
& & & & \\
$\delta_{2}$ & $\delta_{2}$ & 0,015 & & \\
\hline
\end{tabular}

Segundo Jamrozik et al. (1997) os valores genéticos por si só não são de muita utilidade para ordenar ou selecionar animais, mas a função dos mesmos pode prover de informações de grande utilidade para a toma de decisões na seleção de animais.

Observa-se uma menor variância residual no último controle individual de produção ( $>180$ dias de lactação). Apesar disto, as classes definidas no modelo apresentaram homogeneidade das 
variâncias residuais, requisito importante para a utilização de modelos de regressão aleatória (Ramirez et al., 1998, Olori et al., 1999).

As estimativas dos coeficientes de regressão aleatória para os efeitos genéticos e de ambiente permanente para uma amostra de 10 vacas ao acaso são apresentadas nas Tabelas 3 e 4, respectivamente. 
Tabela 3. Estimativa dos coeficientes de regressão aleatória para os efeitos genético aditivos para produção de leite $(\mathrm{kg})$ em 10 animais

\begin{tabular}{ccccc}
\hline $\begin{array}{c}\text { Número de } \\
\text { Animal }\end{array}$ & $\begin{array}{c}\text { Número de } \\
\text { Controles }\end{array}$ & $\hat{\mathrm{a}}_{0 i}{ }^{*}$ & $\hat{\mathrm{a}}_{1 \mathrm{i}}{ }^{*}$ & $\hat{\mathrm{a}}_{2 \mathrm{i}}{ }^{*}$ \\
\hline 124 & 15 & $-0,3748$ & 0,0683 & 0,1241 \\
130 & 15 & 0,1911 & 0,3504 & 0,1053 \\
139 & 21 & $-0,0719$ & 0,0944 & 0,1647 \\
142 & 7 & $-0,7394$ & -02484 & 0,0948 \\
164 & 22 & $-0,1077$ & $-0,1787$ & $-0,0463$ \\
192 & 15 & 0,2887 & $-0,0069$ & 0,0587 \\
196 & 15 & $-0,5531$ & $-0,0594$ & $-0,1054$ \\
& & & & $-0,0702$ \\
230 & 8 & 0,5214 & $-0,0109$ & 0,1353 \\
292 & 7 & $-0,2983$ & 0,2583 & 0,0679 \\
297 & 7 & $-0,1914$ & 0,2863 & \\
\hline
\end{tabular}

$\hat{a}_{0 i}:$ Intercepto, $\hat{a}_{1 i}$ : parâmetro linear, $\hat{a}_{2 i}$ : parâmetro quadrático 
Tabela 4. Estimativa dos coeficientes de regressão aleatória para os efeitos de ambiente permanente sobre a produção de leite $(\mathrm{kg})$ de 10 animais

\begin{tabular}{ccccc}
\hline $\begin{array}{c}\text { Número de } \\
\text { Animal }\end{array}$ & $\begin{array}{c}\text { Número de } \\
\text { Controles }\end{array}$ & $p_{0 i}$ & $p_{1 i}$ & $p_{2 i}$ \\
\hline 124 & 15 & $-0,0309$ & $-0,0386$ & $-0,0351$ \\
130 & 15 & 0,3239 & 0,0398 & 0,5818 \\
139 & 21 & 0,4295 & 0,0238 & 0,0931 \\
142 & 7 & $-0,5503$ & $-0,0531$ & $-0,0796$ \\
164 & 22 & $-0,2451$ & 0,0238 & 0,0931 \\
192 & 15 & 0,6324 & 0,0421 & 0,1159 \\
196 & 15 & $-0,4796$ & $-0,0799$ & $-0,0778$ \\
& & & & 0,0709 \\
230 & 8 & 0,4747 & 0,0421 & $-0,0161$ \\
292 & 7 & $-0,1578$ & $-0,0063$ & $-0,0492$ \\
297 & 7 & $-0,2902$ & $-0,0080$ & \\
\hline
\end{tabular}

$p_{0}:$ Intercepto, $p_{1 i}$ : parâmetro linear, $p_{2 i}$ : parâmetro quadrático

Observa-se grande variabilidade para os coeficientes de regressão aleatória na produção de leite tanto para os valores genéticos quanto para os ambientais. Estes resultados concordam com o publicado por Jamrozik et al (1997), onde as maiores variabilidades observadas corresponderam ao intercepto. 
As médias e desvios dos valores genéticos estimados para a produção de leite em cada controle realizado são apresentados no figura 1.

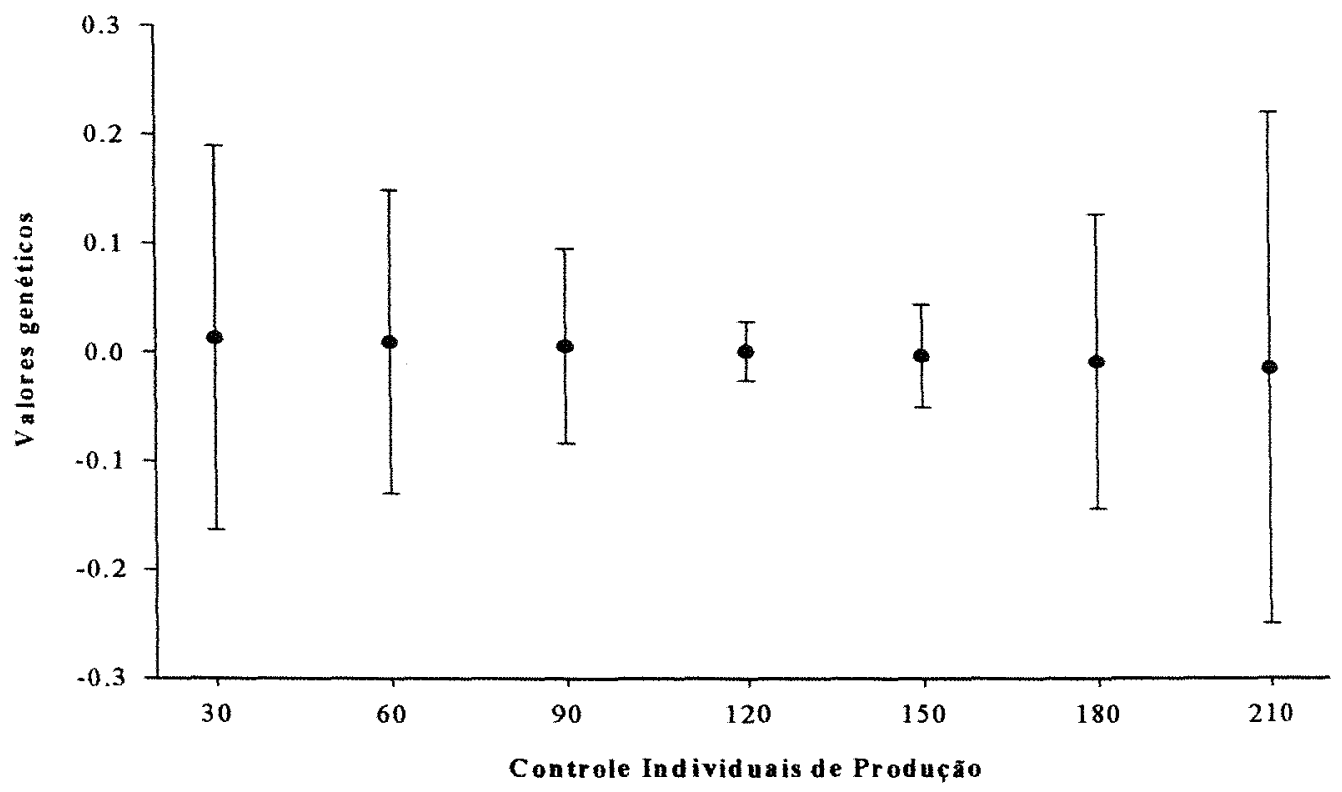

Figura 1. Médias e desvios padrão dos valores genéticos estimados para a produção de leite em cada controle individual de produção.

As médias estimadas foram similares nos valores genéticos estimados em cada dia de controle individual de produção. Os maiores desvios observados corresponderam aos controles no início e final da lactação, reduzindo a variabilidade na metade da lactação. A variabilidade no início e final da lactação corresponde às diferenças genéticas em produção de leite para gado de corte no pico da lactação e na persistência da produção.

No figura 2 são apresentadas as estimativas de herdabilidades para a produção de leite nos controles individuais de produção. 


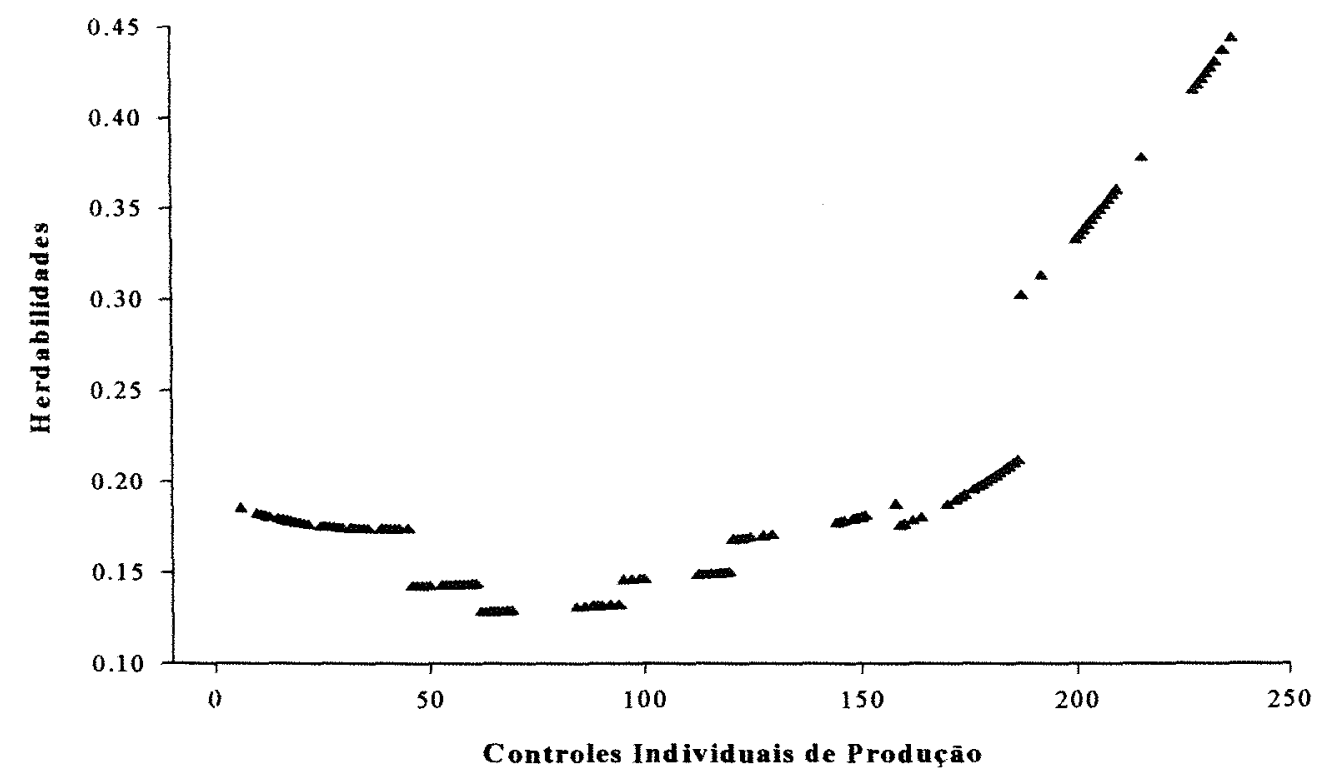

Figura 2. Estimativas da herdabilidade da produção de leite para cada dia de controle individual de produção.

As estimativas das herdabilidades para os diferentes controles leiteiros parecem seguir uma tendência similar à publicada por Ketunnen et al. (1998) e Olori et al (1999) com valores levemente superiores no começo e claramente maiores no final da lactação.

A magnitude dos valores observados de herdabilidade neste trabalho (0.23-0.41) seguem as tendências encontradas na literatura (Jamrozik e Schaeffer, 1997; Ketunnen et al., 1998; Olori et al., 1999) com valores que oscilaram entre 0.19 a 0.59 .

No entanto é importante ressaltar que estes trabalhos referiam-se a dados provenientes de raças leiteiras, entanto que este trabalho analisou a produção de leite de vacas especializadas na produção de carne.

Estas estimativas são mais semelhantes quando comparadas às publicadas por El Faro et al. (1999) trabalhando com vacas da raça Caracu e por Strabel e Misztal (1999) estudando a lactação de vacas de duplo propósito $(0,28-0,55$ e $0,19-0,26)$, e ao contránio do observado por Gengler et al. (1999) as estimativas superiores e inferiores da herdabilidade foram encontrados no final e metade da lactação respectivamente. 
As estruturas de (co)variâncias genéticas aditivas

ambiente permanente e fenotípicas

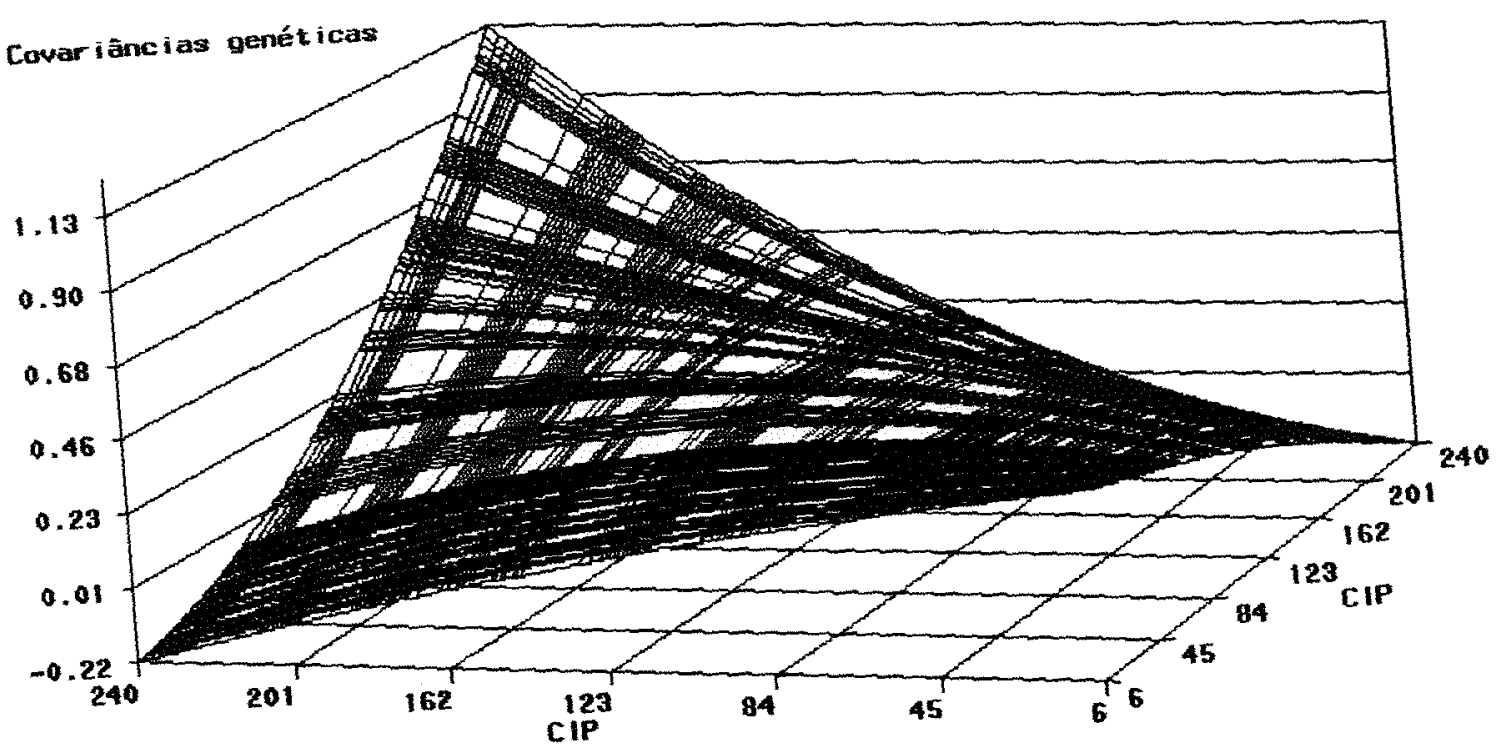

Figura 3. (Co)variâncias genético aditivas para a produção de leite nos controles individuais de produção.

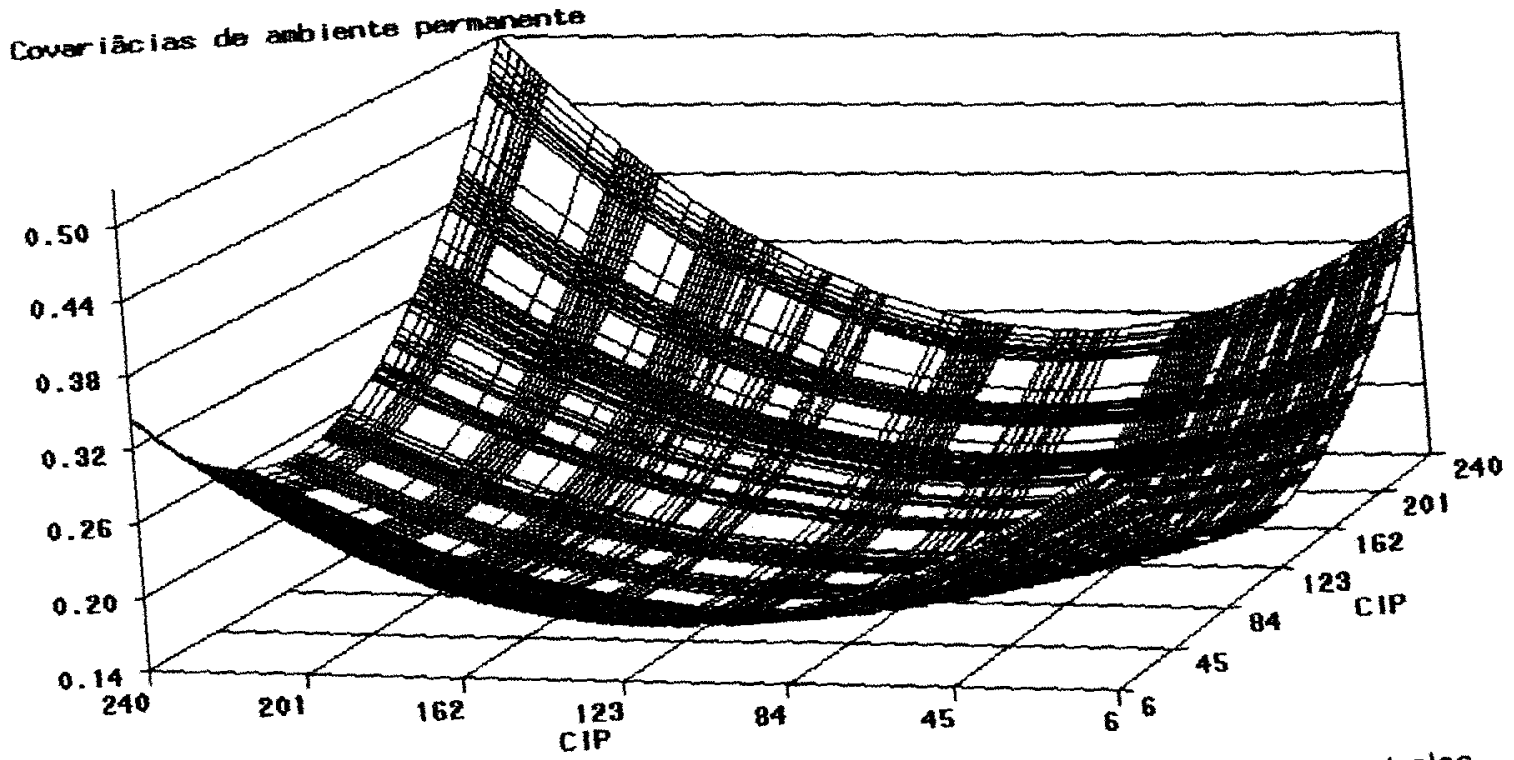

Figura 4. (Co)variâncias de ambiente permanente para a produçăo de leite nos controles individuais de produçäo. 


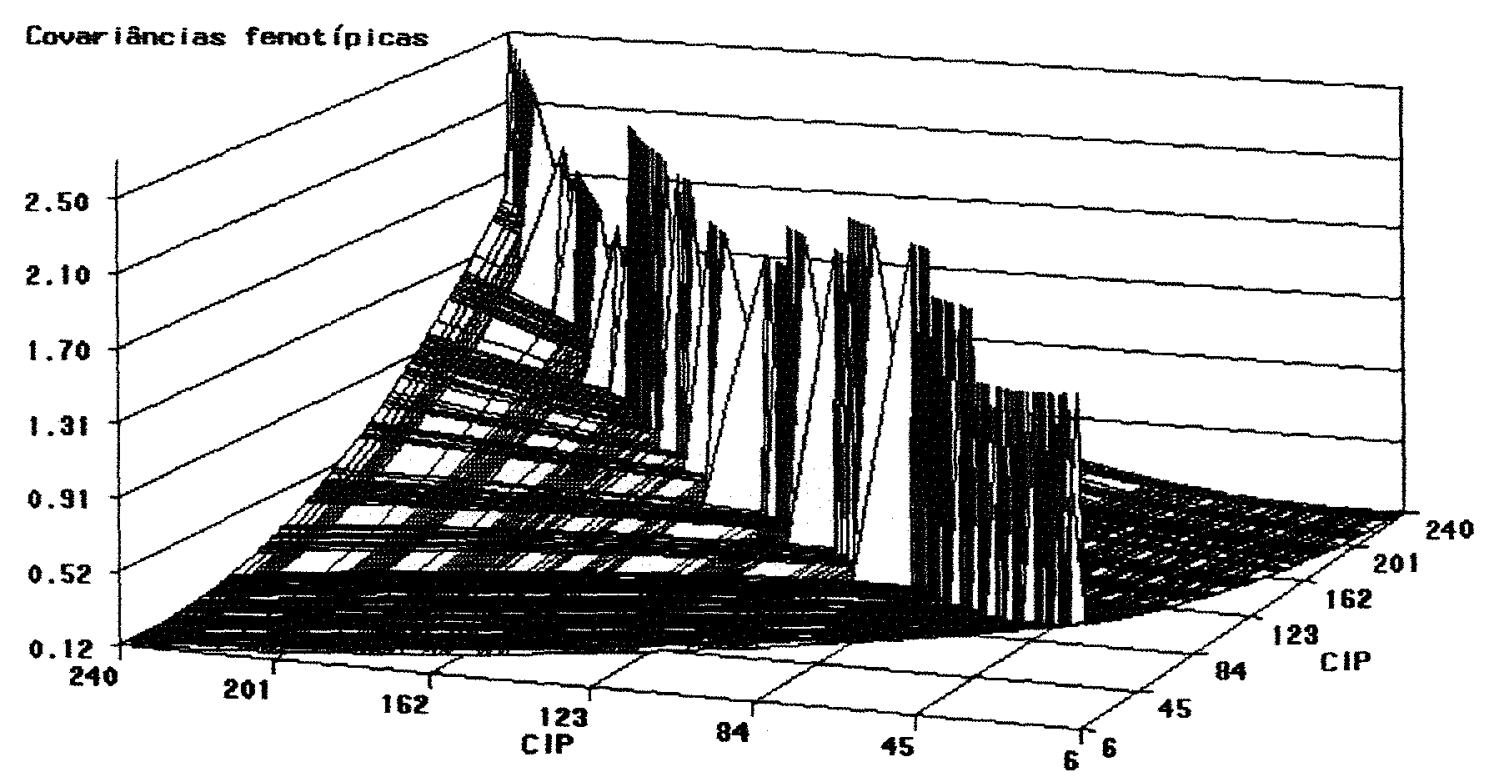

Figura 5. (Co)variâncias fenotipicas para a produção de leite nos controles individuais de produção.

As variâncias genéticas aditivas foram inferiores no inicio e aumentaram no final da lactação. Esta tendência é diferente da encontrada por Shahrbabak (1997) com valores superiores no começo e final da lactação. Este fato em conjunto com as menores variâncias totais observadas no final da lactação (figura 4) explicam os altos valores de herdabilidade observados no figura 1. A herdabilidade segue um padrão similar ao observado para as variâncias fenotípicas e ambientais, com valores levemente superiores no começo, inferiores no meio e claramente superiores no final da lactação, conforme evidenciado nos figuras 3,4 e 5 .

Por outro lado, as variâncias ambientais como era esperado apresentaram valores superiores no começo e final da lactação, comprovando as diferenças observadas em produção devidas ao ambiente antes e durante o pico da lactação, assim como na persistência da produção.

Nos figuras 6, 7 e 8 são apresentados as estimativas das correlações genéticas, de ambiente permanente e fenotípicas obtidas entre os diferentes controle individuais de produção. 


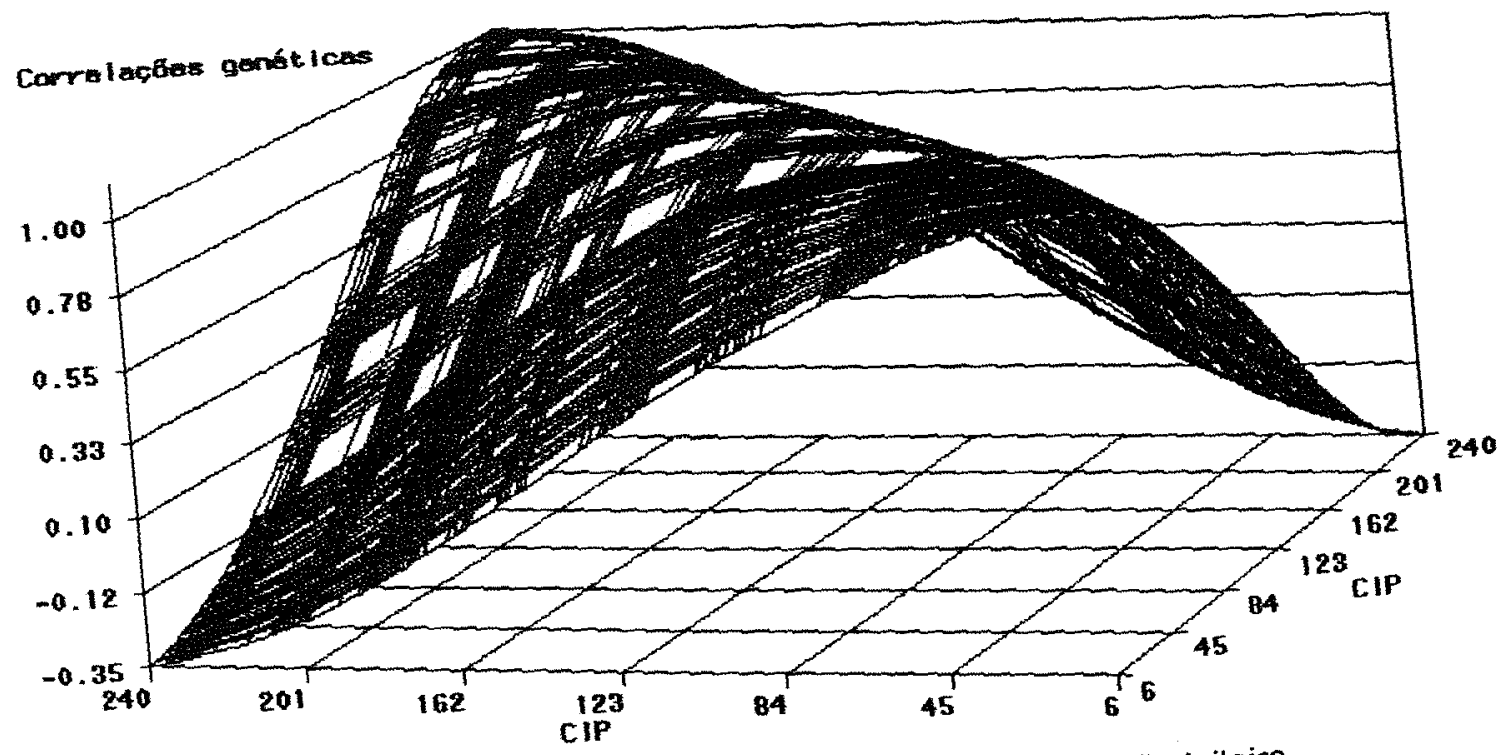

Figura 6. Correlações genéticas entre os controles individuais de produção leiteira.

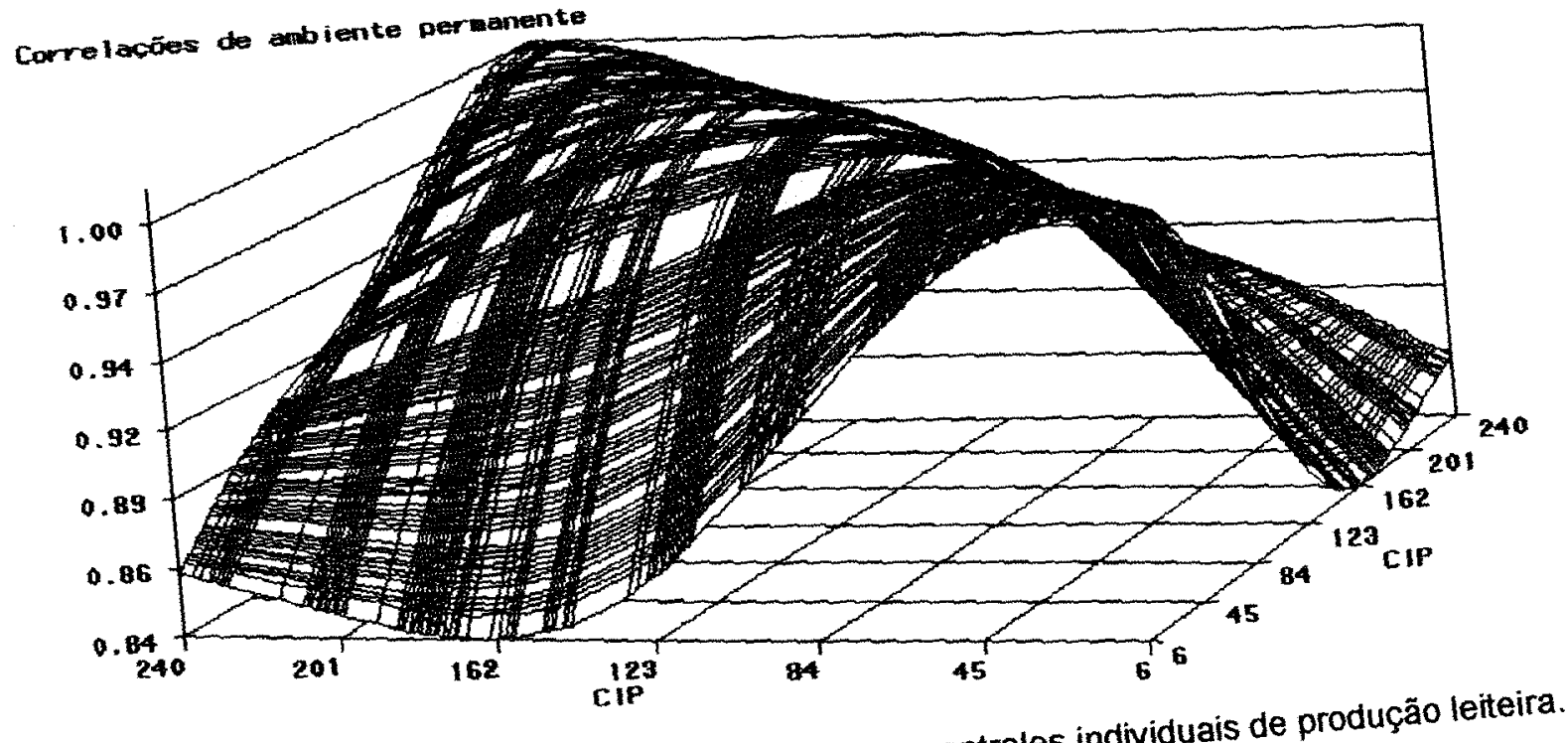

Figura 7. Correlações de ambiente permanente entre os controles individuais de produção leiteira. 


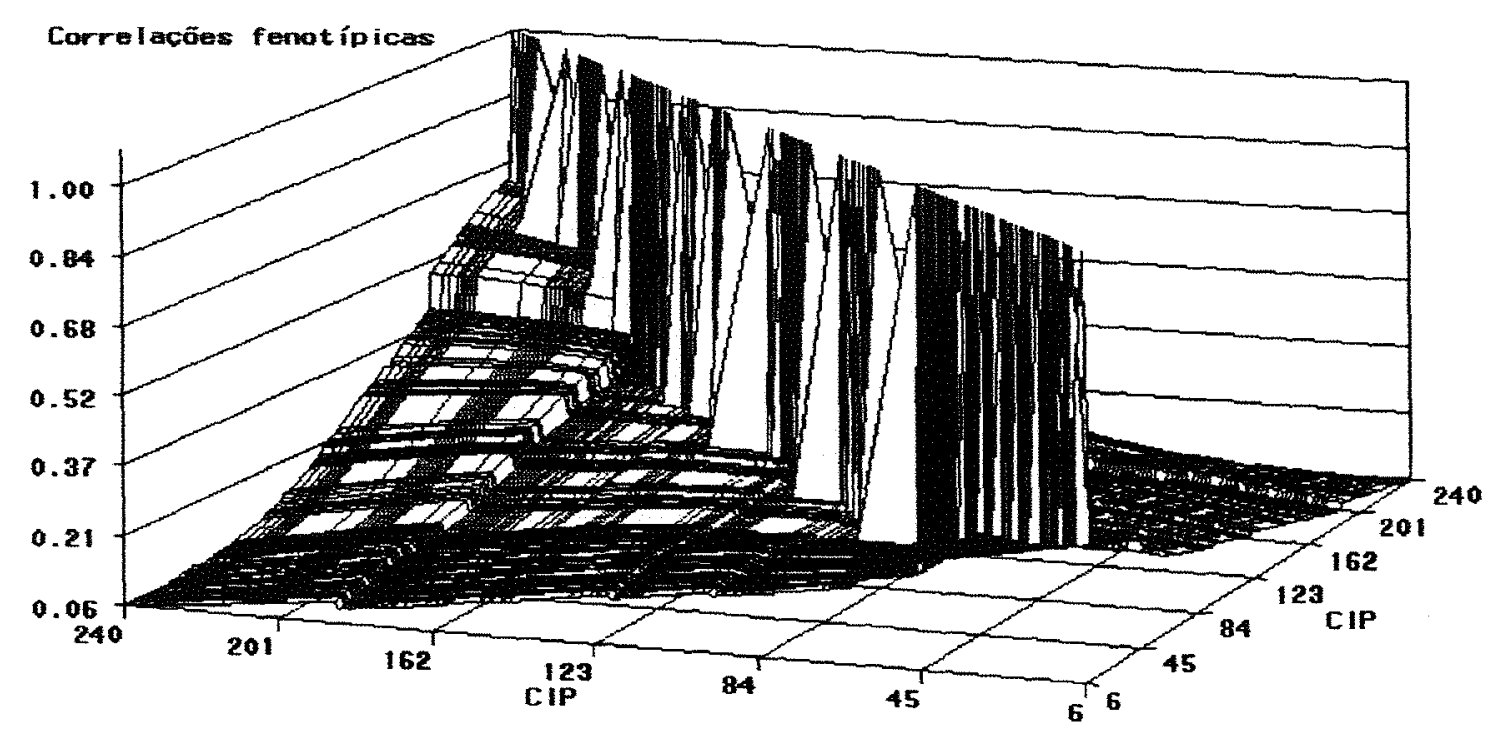

Figura 8. Correlações fenotípicas entre os controles individuais de produção leiteira.

As correlações genéticas apresentam valores altos e positivos entre controles sucessivos $(0,98-1,0)$, diminuindo na medida que se distanciam chegando até valores negativos quando os intervalos superam os 200 dias (Shahrbabak, 1997; Ketunnen et al., 1998 e El Faro et al., 1999).

Ao contrário do encontrado por Olori et al. (1999) observam-se valores baixos e até negativos para as correlações genéticas entre os controles realizados em estádios iniciais e finais da lactação (30-230). No entanto é importante ressaltar que em gado de corte a duração da lactação na maioria dos casos não deveria superar os 180 dias para obter maiores eficiências nos sistemas de produção. Nesse contexto, as correlações genéticas observadas entre o início e a metade da lactação (120-150 dias) apresentam valores médios (0,78-0,60), indicando que a seleção baseada na produção de leite em estádios iniciais da lactação pode apresentar um efeito positivo para a produção de leite no final da lactação.

Uma tendência similar às correlações genéticas foi observada para as correlações de ambiente permanente. No entanto, as correlaçōes fenotípicas mostraram uma tendência diferente às ambientais e genéticas com valores médios inferiores mesmo entre controles sucessivos $(0,26)$.

De um modo similar aos resultados obtidos por Olori et al. (1997) as correlações genéticas foram consistentemente superiores às fenotipicas, diminuindo com o incremento dos intervalos entre os controles. Provavelmente o baixo número de controles realizados durante a lactação tenha contribuído com os reduzidos valores encontrados para as correlações fenotípicas. 


\section{CONCLUSÕES}

As estimativas para herdabilidade da produção de leite nos controles individuais da produção seguem tendências semelhantes às encontradas na literatura, com valores de magnitude moderada.

As correlações genéticas entre controles leiteiros sucessivos foram altas e positivas, diminuindo até se tomarem negativas quando os intervalos superaram os 200 dias. 


\section{REFERÊNCIAS BIBLIOGRÁFICAS}

DURÃES, M.C.; TEIXEIRA, N.M.; FREITAS, A.F. de. Curvas de lactação de vacas da raça Holandesa mantidas em confinamento total. Arquivo Brasileiro de Medicina Veterinária e Zootecnia, v. 43, n. 5, p. 447-458, 1991.

EL FARO, L.; FRIES, L.A.; ALBUQUERQUE, L.G. Estimação de parâmetros Genéticos para Produção no dia do Controle através de Regressão Aleatória. In: REUNIÃO ANUAL DA SOCIEDADE BRASILEIRA DE ZOOTECNIA, 37, 1999, Porto Alegre. Anais,,,Porto Alegre:SBZ, 1999.

GENGLER, N.; TIJANI, A.; WIGGANS, G.R.; MISZTAL, I. Estimation of (Co)variance Function Coefficients for Test Day Yield with a Expectation-Maximization Restricted Maximum Likelihood Algorithm. Journal of Dairy Science, 1998.

JAMROZIK, J.; SCHAEFFER, L.R. Estimates of Genetics Parameters for a Test Day Model with Random Regressions for Yield Traits of First Lactation Holsteins. Journal of Dairy Science, v. 80 , n. 4, p. $762-770,1997$.

JAMROZIK, J.; SCHAEFFER, L.R.; DEKKERS, J.C.M. Genetic Evaluation of Dairy Cattle Using Test Day Yields and random Regression Model. Journal of Dairy Science, v. 80, n. 6, p. 1217-1226, 1997.

JUNQUEIRA, L.V.; NRIVS, R.S.; VEIGA, R.D.; TEIXEIRA, R.M.; DURÃES, M.C.; LOPES, M.A. Estudo das Curvas de Lactação de Vacas Holandesas de atguns Rebanhos do Estado de Minas Gerais, por intermédio de uma Função Gama Incompleta. Revista Brasileira de Zootecnia, v. 26, n. 6, p. 1109-1118, 1997.

KETTUNEN, A.; MÄNTYSAARI, E.A.; STRANDEN, I. PÖSÖ, J.; LIDAUER, M. Estimation of Genetic Parameters for First Lactation Test Day Milk Production Using Random Regression Models. In: World Congress Genetic Applied Livestock Production, 6, Armnidale, Australia,1998. [CD - rom]. 
MEYER, K. "DXMRR" - a program to estimate covariance functions for longitudinal data by restricted maximum likelihood. In: World Congress Genetic Applied Livestock Production, 6 , Armnidale, Australia. Proceedings... Armindale, v. 27, p. 465-466, 1998.

MEYER, K. DFREML: User Notes (Manual para utilização do programa). Versão 3.0. 29 p. 1998.

MEYER, K. Random regressions to model phenotypic variation in monthly weights of Australian beef cows. Livestock Production Science, v. 65, p. 19-38, 2000.

OLORI, V.E.; HILL, W.G.; MCGUIRK, B.J.; BROTHERSTONE, S. Estimating variance components for test day milk records by restricted maximum likelihood with a random regression animal model. Livestock Production Science, v. 61, p. 53-63, 1999.

RAMIREZ, G.; RAMÍREZ, R.; NÚÑEZ, R. Mínimos cuadrados ponderados en la estimación de curvas de lactância de ganado bovino. Agrociencia, v. 32, p. 267-271, 1998

STRABEL, T.; MISZTAL, I. Genetic Parameters for First and Second Lactation Milk Yields of Polish Black and White Cattle. Journal of Dairy Science, v. 82, n. 12, p. 2805-2810, 1999.

SHAHRBABAK, M.M. Feasibility of random regression models for Iranian Holstein test day records. Guelph, 1997. 138 p. Thesis (Ph. D.) - University of Guelph.

VARONA, L.; MORENO, C.; GARCIA CORTES, L.A.; ALTARRIBA, J. Bayesian Analysisof Wood's Lactation Curve for Spanish Dairy Cows. Journal of Dairy Science, v. 81, n. 5, p. 1469-1478, 1998.

WOOD, P.D.P. Algebraic model of the lactation model in cattle. Nature, v. 216, p. 164-165, 1967. 


\section{CAPITULOV V CONCLUSÕES GERAIS}

A produção de leite apresentou efeito significativo do momento da lactação e da interação sistema de produção por momento da lactação.

A produção de leite durante a fase pré desmama não teve relação direta com o comportamento de amamentação nem o ganho de peso dos bezerros dos diferentes sistemas de produção.

Condições deficientes de alimentação não resultaram em menores produçōes de leite de vacas Nelore, mas sim em acentuadas perdas de peso.

O tempo diário de amamentação apresentou quedas significativas no sistema extensivo durante a lactação, enquanto que os sistemas intensivos não mudam ou aumentam os minutos de amamentação por dia.

Para as condições nas quais o experimento foi desenvolvido, os bezerros cruzados apresentaram os melhores desempenhos durante a fase pré desmama, em comparação com os sistemas

As estimativas para herdabilidade da produção de leite nos controles individuais da produção seguem tendências semelhantes às encontradas na titeratura, com valores de magnitude moderada.

As correlações genéticas entre controles leiteiros sucessivos foram altas e positivas, diminuindo até se tomarem negativas quando os intervalos superaram os 200 dias. 


\section{REFERÊNCIAS BIBLIOGRÁFICAS}

ALBUQUERQUE, L.G. de; ELER, J.P.; COSTA, M.R.P. da; SOUZA, R.C. Produção de Leite e desempenho do Bezerro na fase de Aleitamento em trés raças bovinas de corte. Revista da Sociedade Brasileira de Zootecnia, v. 22, n. 5, p. 745-754, 1993.

ALENCAR, M.M.; JUNQUEIRA, A.A.F.; PARANHOS, N.E. Produção de leite em vacas da raça Canchim. Revista da Sociedade Brasileira de Zootecnia, v. 14, n. 3, p. 358-366, 1985.

ALENCAR, M.M.; Efeitos da produção de leite sobre o desenvolvimento de bezerros canchim. Revista da Sociedade Brasileira de Zootecnia, v. 16, n. 1, p. 1-13, 1987.

ALENCAR, M.M.; RUZZA, F.J.; PORTO, E.J.S. Desempenho produtivo de fêmeas das raças Canchim e Nelore. III. produção de leite. Revista da Sociedade Brasileira de Zootecnia, v. 17 , n. 4 , p. $317-328,1988$.

ALENCAR, M.M. Relação entre produção de leite da vaca e desempenho do bezerro nas raças Canchim e Nelore. Revista da Sociedade Brasileira de Zootecnia, v. 18, n. 2, p. 146156, 1989.

ALENCAR, M.M.; RIBEIRO, R.P.; VERISSIMO, C.J.; DURAM, J.T.; MORO, M.E.G. Efeitos da produção de leite das vacas sobre o desenvolvimento pós desmama de bezerros da raça Canchim. Pesquisa Agropecuária Brasileira, Brasilia, v. 27, n. 1, p. 105-110, 1992.

ALENCAR, M.M.; OLIVEIRA, F.T.T. de; TAMBASCO, A.J.; DA COSTA, J.L.; BARBOSA, R.T.; BUGNER, M. Desenvolvimento pós-desmama e eficiência reprodutiva pós-parto em gado de corte: influência da produção de leite. Revista da Sociedade Brasileira de Zootecnia, v. 22, n. 6, p. 1012-1018, 1993.

ALENCAR, M.M.; CRUZ, G.M. da; TULLIO, R.R.; CORREA, L.A. Características da amamentação de bezerros da raça Canchim e cruzados Canchim x Nelore. Revista da Sociedade Brasileira de Zootecnia, v. 24, n. 5, p. 706-714, 1995. 
ALENCAR, M.M.; TULLIO, R.R; CRUZ, G.M.; OLIVEIRA, M.C.S. Produção de leite da vaca e desenvolvimento do bezerro em gado de corte. Revista da Sociedade Brasileira de Zootecnia, v. 25, n. 1, p. 92-101, 1996.

BEAL, W.E.; NOTLER, D.R.AKERS, R.M. Techniques for estimation of Milk Yield in Beef Cows and Relationships of Postpartum Reproduction. Journal of Animal Science, v. 68, p. 937$943,1990$.

CRUZ, G.M., ALENCAR, M.M., TULLIO, R.R. Produção de leite de vacas das raças Canchim e Nelore. Revista Brasileira de Zootecnia, v. 26, n. 5, p. 887-893, 1997.

DAS, S.M.; REDBO, 1.; WIKTORSSON, H. 2000. Effect of age of calf on suckling behaviour and other behavioural activities of Zebu and crossbred calves during restricted suckling periods. Applied Animal Behaviour Science, v. 67, Issues 1-2, p. 47-57.

DAY, M.L.; IMAKAWA, K.; CLUTTER, A.C.; WOLFE, P.L.; ZALESKY, D.D.; NIELSEN, M.K.; KINDER, J.E. Suckling Behavior of Calves with Dams varying in Milk Production. Journal of Animal Science, v. 65, p. 1207-1212, 1987.

DURÄES, M.C.; TEIXEIRA, N.M.; FREITAS, A.F. de. Curvas de lactação de vacas da raça Holandesa mantidas em confinamento total. Arquivo Brasileiro de Medicina Veterinária e Zootecnia, v. 43, n. 5 , p. 447-458, 1991.

EL FARO, L.; FRIES, L.A.; ALBUQUERQUE, L.G. Estimação de parâmetros Genéticos para Produção no dia do Controle através de Regressão Aleatória. In: XXXVI Reunião da Sociedade Brasileira de Zootecnia, 26-29 de julho de 1999, Porto Alegre, RS.

EUCLIDES FILHO, K.; FIGUEIREDO, G.R. de; EUCLIDES, V.P.B. Efíciência de produção de vacas de corte com diferentes potenciais para produção de leite. Pesquisa Agropecuária Brasileira, Brasilia, v. 30, n. 7, p. 1003-1007, 1995.

FISS, C.F.; WILTON, J.W. Contribution of Breed, Cow Weight, and Milk Yield to the traits of Heifers and Cows in Four Beef Breeding Systems. Journal of Animal Science, v. 70, p. 3686-3696, 1992. 
FISS, C.F.; WILTON, J.W. Contribution of Breed, Cow Weight, and Milk Yield to the Preweanning, Feedlot and Carcass Traits of Calves in Three Beef Breeding Systems. Journal of Animal Science, v. 71, p. 2874-2884, 1993.

GENGLER, N.; TIJANI, A.; WIGGANS, G.R.; MISZTAL, I. Estimation of (Co)variance Function Coefficients for Test Day Yield with a Expectation-Maximization Restricted Maximum Likelihood Algorithm. Journal of Dairy Science, 1998.

GRINGS, E.E.; SHORT, R.E.; MCNEIL, M.D.; HAFERAMP, M.R.; ADAMS. D.C. Efficiency of Production in Cattle of Two Growth Potencials on Northorn Great Plains Rangelands During Spring-Summer Grazing. Journal of Animal Science, v. 74, p. 2317-2326.

JAMROZIK, J.; SCHAEFFER, L.R. Estimates of Genetics Parameters for a Test Day Model with Random Regressions for Yield Traits of First Lactation Holsteins. Journal of Dairy Science, v. 80, n. 4, p. 762-770, 1997.

JAMROZIK, J.; SCHAEFFER, L.R.; DEKKERS, J.C.M. Genetic Evaluation of Dairy Cattle Using Test Day Yields and random Regression Model. Journal of Dairy Science, v. 80, n. 6, p. 1217-1226, 1997.

JENKINS, T.G.; FERREL, C.L. Lactation Characteristics of Nine Breeds of Cattle Fed Various Quantities of Dietary Energy. Journal of Animal Science, v. 70, p. 1652-1660, 1992.

JUNQUEIRA, L.V.; NRIVS, R.S.; VEIGA, R.D.; TEIXEIRA, R.M.; DURÃES, M.C.; LOPES, M.A. Estudo das Curvas de Lactação de Vacas Holandesas de alguns Rebanhos do Estado de Minas Gerais, por Intermédio de uma Função Gama Incompleta. Revista Brasileira de Zootecnia, v. 26, n. 6, p. 1109-1118, 1997.

KETTUNEN, A.; MÄNTYSAARI, E.A.; STRANDÉN, I. PÖSÖ, J.; LIDAUER, M. Estimation of Genetic Parameters for First Lactation Test Day Milk Production Using Random Regression Models. In: World Congress Genetic Applied Livestock Production, 6, Armnidale, Australia,1998. [CD - rom].

KRESS, D.D.; DOORNBOS, D.E.; ANDERSON, D.C. Performance of Crosses Among Hereford, Angus and Simmental Cattle with different levels of Simmental Breeding: $V$. Calf 
production, Milk Production and Reproduction of three-to-eight-year-old dams. Journal of Animal Science, v. 68, p. 1910-1921, 1990.

KRESS, D.D.; DOORNBOS, D.E.; ANDERSON, D.C.; DAVIS, K.C. Genetic Components for Milk Production of Tarentaise, Hereford, and Tarentaise $x$ Hereford Cows. Journal of Animal Science, v. 74, p. 2344-2348, 1996.

MALLINCKRODT, C.H.; BOURDON, R.M.; GOLDEN, B.L; SCHALLES, R.R.; ODDE, K.G. Relationships of Maternal Milk Expected Progeny Differences to Actual Milk Yield and Calf Weaning Weight. Journal of AnimalScience, v. 71, p. 355-362, 1993.

MARSTON, T.T.; SIMMS, D.D.; SCHALLES, R.R.; ZOELLNER, K.O; MARTIN, L.C.; FINK, G.M. Relationship of Milk Production, Milk Expected Progeny Difference, and Calf Weaning Weight in Angus and Simmental Cow-Calf Pairs. Joumal of Animal Science, v. 70, p. 3304-3310.

Mc KAY, R.M.; RAHNEFELD, G.W.; WEISS, G.M.; FREDEEN, H.T.; LAWSON, J.E.; NEWMAN, J.A.; BAILEY, D.R.C. Milk Yield and Composition in First-cross and Back-cross Beef Cows. Canadian Journal of Animal Science, v.74, p. 209-216, 1994.

MCMORRIS, M.R.; WILTON, J.W. Breeding System, Cow Weight and Milk Yield Effects on Various Biological Variables in Beef Production. Journal of Animal Science, v. 63, p. 1361$1372,1986$.

MEYER, K. "DXMRR" - a program to estimate covariance functions for longitudinal data by restricted maximum likelihood. In: World Congress Genetic Applied Livestock Production, 6, Armnidale, Australia. Proceedings... Armindale, v. 27, p. 465-466, 1998.

MEYER, K. Random regressions to model phenotypic variation in monthly weights of Australian beef cows. Livestock Production Science, v. 65, p. 19-38, 2000.

MILLER, S.P.; WILTON, J.W.; PFEIFFER, W.C. Effects of Milk Yield on Biological Efficiency and Profit of Beef Production from Birth to Slaughter. Journal of Animal Science, v. 77, p. 344-352, 1999. 
MONDRAGON, I.; WILTON, J.W.; ALLEN, O.B.; SONG, H. stage of Lactation Effects, Repeteabilities and Influences on Weaning Weights of Yield and Composition of Milk in Beef Cattle. Canadian Joumal of Animal Science, v. 63, p. 751-761, 1983.

MONTAÑO BERMUDEZ, M.; NIELSEN, M.K. Biological efficiency of weaning and to slaughter of crossbred beef cattle with different genetic potential of milk. J. Anim. Sci, v. 68, p. 2297-2309, 1990.

OLORI, V.E.; HILL, W.G.; MCGUIRK, B.J.; BROTHERSTONE, S. Estimating variance components for test day milk records by restricted maximum likelihood with a random regression animal model. Livestock Production Science, v. 61, p. 53-63, 1999.

ODDE, K.G.; KIRACOFE, G.H.; SCHALLES, R.R. Suckling Behavior in Range Beef Calves. Joumal of Animal Science, v. 61, n. 2, p. 307-309, 1985.

QUADROS, S.A.F. de; LOBATO, J.F.P. Efeitos da Lotação Animal na Produção de Leite de Vacas de Corte primiparas e no Desenvolvimento de seus Bezerros. Revista Brasileira de Zootecnia, v. 26, n. 1, p. 27-33, 1997.

RAMIREZ, G.; RAMIREZ, R.; NÚÑEZ, R. Mínimos cuadrados ponderados en la estimación de curvas de lactância de ganado bovino. Agrociencia, 32:267-271, 1998

REINHARDT, V.; REINHARDT, A. Natural suckling performance and age of weaning in zebu cattle (Bos Indicus). Joumal of Agricultural Science, Camberra, v. 96, p. 309-312, 1981.

RIBEIRO, E.L.A.; RESTLE, J.; PIRES, C.C. Produção e composição do leite em vacas Charolês e Aberdeen Angus amamentando terneiros puros ou mestiços. Pesquisa Agropecuária Brasileira, Brasília, 26( 8):1267-1273, 1991.

SHAHRBABAK, M.M. Feasibility of random regression models for Iranian Holstein test day records. Guelph, 1997, 138 p. Thesis (Ph. D.) - University of Guelph.

SINCLAIR, K.D.; YILDIZ, S.; QUINTANS, G.; BROADBENT, P.J. Annual energy intake and the performance of beef cows differing in body size and milk potential. Animal Science, $v$. 66, p. $643-655,1998$. 
STRABEL, T.; MISZTAL, I. Genetic Parameters for First and Second Lactation Milk Yields of Polish Black and White Cattle. Joumal of Dairy Science, v. 82, n. 12, p. 2805-2810.

van OIJEN, M.; MONTAÑO-BERMUDEZ, M.; NIELSEN, M.K. Economical and Biological Efficiences of Beef Cattle Differing in Level of Milk Production. Journal of Animal Science, v. 71, p. $44-50,1993$.

VARONA, L.; MORENO, C.; GARCIA CORTES, L.A.; ALTARRIBA, J. Bayesian Analysis of Wood's Lactation Curve for Spanish Dairy Cows. Journal of Dairy Science, v. 81, n. 5, p. 1469-1478, 1998.

WILLIAMS, J.H.; ANDERSON, D.C.; KRESS, D.D. Milk Production in Hereford Cattle. I. Effects of Separation interval on Weight-Suckle-Weight Milk Production Estimates. Journal of Animal Science, v. 49, n.6., 1979.

WOOD, P.D.P. Algebraic model of the lactation model in cattle. Nature, v. 216, p. 164-165, 1967.

YOKOI, N.; MORIYA, K.; SASAKI, Y. A mesure for predicting genetic merit for milking and nursing ability in beef cattle. Animal Science, v. 65, p. 39-43, 1997. 